This item was submitted to Loughborough's Research Repository by the author.

Items in Figshare are protected by copyright, with all rights reserved, unless otherwise indicated.

\title{
Electrochromic organic and polymeric materials for display applications
}

PLEASE CITE THE PUBLISHED VERSION

PUBLISHER

(C) Elsevier

LICENCE

CC BY-NC-ND 4.0

\section{REPOSITORY RECORD}

Mortimer, Roger J., Aubrey L. Dyer, and John R. Reynolds. 2019. "Electrochromic Organic and Polymeric Materials for Display Applications". figshare. https://hdl.handle.net/2134/1046. 
This item was submitted to Loughborough's Institutional Repository by the author and is made available under the following Creative Commons Licence conditions.

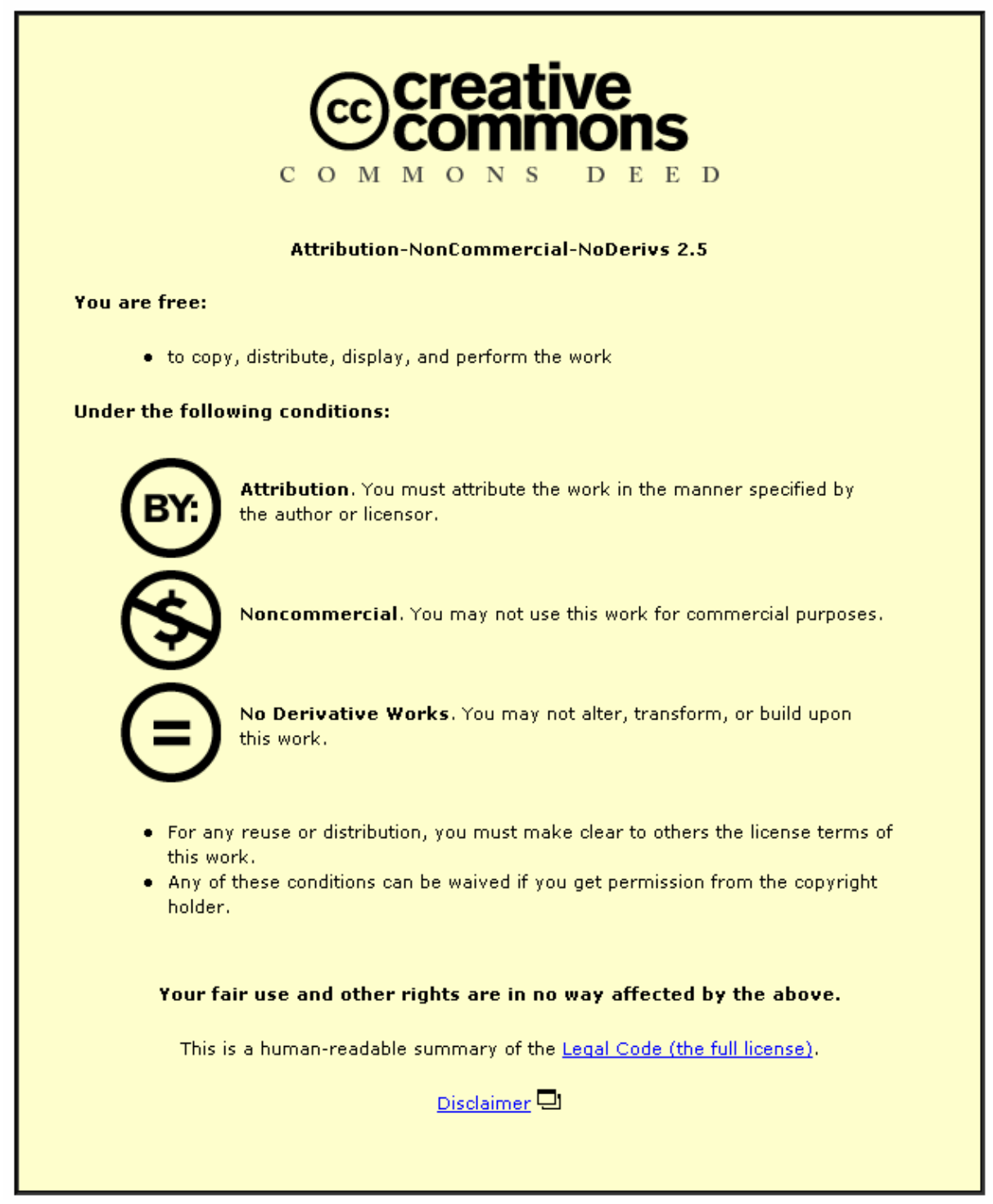

For the full text of this licence, please go to: http://creativecommons.org/licenses/by-nc-nd/2.5/ 


\title{
Invited review article for 'Displays' special issue on Organic/Polymeric
}

Displays. Revised manuscript, submitted March 1, 2005.

\section{Electrochromic Organic and Polymeric Materials for Display Applications}

\author{
Roger J. Mortimer*†, Aubrey L. Dyer, John R. Reynolds \\ The George and Josephine Butler Polymer Research Laboratory, Department of Chemistry, \\ Center for Macromolecular Sciences and Engineering, University of Florida, Gainesville,
} Florida 32611 USA

\begin{abstract}
An electrochromic material is one where a reversible color change takes place upon reduction (gain of electrons) or oxidation (loss of electrons), on passage of electrical current after the application of an appropriate electrode potential. In this review the general field of electrochromism is introduced, with coverage of the types, applications, and chemical classes of electrochromic materials and the experimental methods that are used in their study. The main classes of electrochromic organic and polymeric materials are then surveyed, with descriptions of representative examples based on transition metal coordination complexes, viologen systems, and conducting polymers. Examples of the application of such organic and polymeric electrochromic materials in electrochromic displays are given.
\end{abstract}

Key words: electrochromism, ECD, electrochromic display, viologen, transition metal coordination complex, metallopolymer, phthalocyanine, conducting polymer.

${ }^{\dagger}$ Permanent address: Dr. R. J. Mortimer, Department of Chemistry, Loughborough University, Loughborough, Leicestershire, LE11 3TU, UK. E-mail: R.J.Mortimer@lboro.ac.uk 


\section{Introduction}

Numerous chemical materials exhibit redox states with distinct electronic (UV/visible) absorption spectra. Where the switching of redox states generates new or different visible region bands, the material is said to be electrochromic. ${ }^{1-4}$ Color changes in an object give visual signals that can be used to convey useful information to an observer. ${ }^{1}$ Furthermore, by selective absorption or transmission of light by a material, the light energy impinging upon an observer can be modulated. ${ }^{1}$ Where a chemical or physical external stimulus causes a reversible color change or variation in light transmission, the possible applications are


causes the change, such as electrochromism, photochromism, thermochromism and gasochromism. An electrochromic material is one where a reversible color change takes place upon reduction (gain of electrons) or oxidation (loss of electrons), on passage of electrical current after the application of an appropriate electrode potential. ${ }^{2-10}$

Many chemical species can be switched between redox states that have distinct electronic absorption spectra. Such spectra arise from either a moderate-energy internal electronic excitation or an intervalence optical charge transfer where the chemical species has two centers of differing valence or oxidation state. ${ }^{2-10}$ While materials are considered to be electrochromic when marked visible color changes are shown under illumination, recent interest in electrochromic devices (ECD’s) for multispectral energy modulation by reflectance and absorbance has extended the definition. ${ }^{11}$ Chemical species are now being studied for modulation of radiation in the near infra-red (NIR), ${ }^{10,12}$ thermal infra-red, ${ }^{13}$ and microwave regions, and 'color' can mean response of detectors to these electromagnetic regions, not just the human eye. ${ }^{11}$ 


\subsection{Types of Electrochromic Materials}

Electrochromic materials are of three basic types. ${ }^{2}$ In a given electrolyte solution, type I materials are soluble in both the reduced and oxidized (redox) states. An example here is the prototype viologen, 1,1'-di-methyl-4,4'-bipyridilium ('methyl viologen'). Type II materials are soluble in one redox state, but form a solid film on the surface of an electrode following electron transfer. An example here is 1,1'-di-heptyl-4,4'-bipyridilium ('heptyl viologen'). In type III materials, such as conductive polymers, both redox states are solids, and such systems are generally studied as thin films on electrode surfaces. For types II and III, once the redox state has been switched, no further charge injection is needed to retain the new electrochromic state and such systems are said to have 'optical memory'. In contrast, for type I electrochromic materials, diffusion of the soluble electrochemically-generated product material away from the electrode occurs and it is necessary to keep current flowing until the whole solution has been electrolyzed. Where more than two redox states are electrochemically accessible in a given electrolyte solution, the electrochromic material may exhibit several colors and be termed polyelectrochromic, a frequent property of electrochromic polymers. ${ }^{2}$

\subsection{Applications of Electrochromic Materials}

Commercial applications of electrochromic materials in devices include anti-glare car rear-view mirrors, ${ }^{4,8}$ electrochromic strips as battery state-of-charge indicators and electrochromic sunglasses. Proposed applications include 'smart windows' (based on modulation of either the transmitted or reflected solar radiation) for use in cars and in buildings, ${ }^{8}$ re-usable price labels, protective eyewear, controllable aircraft canopies, glarereduction systems for offices, devices for frozen-food monitoring, ${ }^{14}$ camouflage materials, 
spacecraft thermal control, and controllable light-reflective or light-transmissive display devices for optical information and storage.

\subsection{Chemical Classes of Electrochromic Material}

There is a vast number of chemical species that show electrochromic properties, ${ }^{2}$ including both metal coordination complexes in solution and as polymer films, ${ }^{10}$ metal oxide films (especially tungsten oxide), ${ }^{2,3}$ viologens (4,4' -bipyridylium salts; in solution and as polymer films $)^{2,15}$ and conducting polymers, ${ }^{2,16-20}$ such as polypyrrole, polythiophene and polyaniline, as thin films. Other classes of electrochromic material include Y, La and Y/La alloys - which switch from a reflecting-mirror metallic state to a transparent semi-conducting phase on hydride formation ${ }^{8,21}$ and metal deposition/stripping systems. ${ }^{2}$ It is important, however, to realize that while many types of chemical species exhibit electrochromism, only those with favorable electrochromic performance parameters ${ }^{2}$ are potentially useful in commercial applications. Thus most applications require electrochromic materials with high contrast ratio, coloration efficiency, cycle life, and write-erase efficiency. Some performance parameters are application dependent; displays need low response times, whereas 'smart windows' can tolerate response times of up to several minutes.

\subsection{Experimental Methods for Studying Electrochromic Materials}

Redox systems which are likely to show promise as electrochromic materials are first studied, either as an electroactive solute or surface film, at an electrochemically inert 'working' electrode, under potentiostatic or galvanostatic control. ${ }^{2}$ Traditional electrochemical techniques ${ }^{22}$ such as cyclic voltammetry (CV), coulometry, and 
chronoamperometry, all partnered by in situ spectroscopic measurements as appropriate, ${ }^{23,24}$ are employed for characterization. In initial studies, three-electrode circuitry is generally employed, with 'counter' and 'reference' electrodes completing the electrical circuit. ${ }^{2}$

For practical ECD investigations, a simple two-electrode circuit is used, with a solid (often polymeric), gel or liquid electrolyte being sandwiched between the 'primary' electrochromic electrode and a charge-balancing 'secondary' electrode, in what is essentially a rechargeable electrochemical cell. Color switching of an ECD takes place on charge/discharge by application of an appropriate electrical potential. Electrode substrates are typically of glass or flexible plastic (generally of poly(ethylene terephthalate) (PET) e.g., Mylar $^{\circledR}$ ) sheet, coated with an optically transparent electrically conducting film (e.g., tindoped indium oxide (ITO), antimony-doped tin oxide, or F-doped tin oxide). Recently, 'allpolymer' electrochromic devices have been reported, ${ }^{25}$ where poly $(3,4-$ (ethylenedioxy)thiophene)-poly(styrene sulfonate) (PEDOT-PSS) as the electrically conducting film is spin-coated on commercial plastic transparency film.

ECD's are designed to operate in either absorptive/transmissive or reflective modes. For absorptive/transmissive devices, the 'secondary' electrode redox reaction is chosen to be a system where there is little perceptible visible color change or as an electrochromic system where the color change is complementary to that at the 'primary' electrochromic electrode. For reflective devices, traditionally, one of the electrodes is silver-backed. More recently, reflective-type ECD's on metallized substrates have been investigated, ${ }^{26-29}$ where patterned electrodes are prepared using line patterning, screen printing and metal vapor deposition techniques. For these devices, the 'secondary' electrode color change is 'hidden'. 


\section{Electrochromic Polymers based on Transition Metal Coordination Complexes}

\subsection{Introduction}

Transition metal coordination complexes are potentially useful as electrochromic materials because of their intense coloration and redox reactivity. ${ }^{10,30}$ Chromophoric properties arise from low-energy metal-to-ligand charge transfer (MLCT), intervalence CT, intraligand excitation, and related visible-region electronic transitions. Because these transitions involve valence electrons, chromophoric characteristics are altered or eliminated upon oxidation or reduction of the complex. Any colored transition metal coordination complex that is redox-switchable within the 'potential window' of a given electrolyte solution will undergo an accompanying color change and will therefore be electrochromic, at least to some extent. While these spectroscopic and redox properties alone would be sufficient for direct use of transition metal coordination complexes in solution-phase ECD's, polymeric systems based on coordination complex monomer units, which have potential use in all-solidstate systems, are frequently investigated.

Electrochemical polymerization is often used to prepare redox active polymer films on electrode surfaces. ${ }^{31}$ This technique has the advantage that a wide variety of conducting substrates can be used, and that film thickness can be directly controlled by the electrochemical potential scan rate, the potential range, polymerization time and the choice of monomer concentration and electrolyte solution. 


\subsection{Reductive Electropolymerization of Polypyridyl Complexes}

Good examples of transition metal coordination complexes that could have potential use in ECD's include the $\left[\mathrm{M}^{\mathrm{II}}(\text { bipy })_{3}\right]^{2+}(\mathrm{M}=$ iron, ruthenium, osmium; bipy = 2,2'-bipyridine $)$ series which are respectively red, orange and green in the M(II) redox state, due to the presence of an intense MLCT absorption band. ${ }^{30}$ Electrochromicity results from loss of the MLCT absorption band on switching to the M(III) redox state. Reductive electropolymerization of suitably substituted $\left[\mathrm{M}^{\mathrm{II}}(\text { bipy })_{3}\right]^{2+}$ complexes allows the preparation of electrochromic redox active polymer films. ${ }^{32}$ This technique relies on the ligand-centered nature of the three sequential reductions of complexes such as $\left[\mathrm{Ru}\left(\mathrm{L}^{2}\right)_{3}\right]^{2+}\left(\mathrm{L}^{2}=4\right.$-vinyl- $4^{\prime}-$ methyl-2,2'-bipyridine (figure 1)), combined with the anionic polymerizability of suitable ligands. ${ }^{32}$ Vinyl-substituted pyridyl ligands such as $\mathrm{L}^{1}-\mathrm{L}^{3}$ are generally employed, although metallopolymers have also been formed from complexes of halo-substituted pyridyl ligands such as 4-(bromomethyl)-4'-methyl-2,2'-bipyridine, via electrochemically initiated carbonhalide bond cleavage. ${ }^{33}$ In either case, electrochemical reduction generates radicals, which lead to carbon-carbon bond formation and oligomerization. Oligomers above a critical size are insoluble and thus thin films of the electroactive metallopolymer are produced on the electrode surface. As noted above, the color of such metallopolymer films in the M(II) redox state may be selected by suitable choice of the metal.

\section{FIGURE 1}

In a novel approach, spatial electrochromism has been demonstrated in metallopolymeric films based on polymeric polypyridyl complexes. ${ }^{34}$ Photolysis of poly $\left[\mathrm{Ru}^{\mathrm{II}}\left(\mathrm{L}^{1}\right)_{2}(\mathrm{py})_{2}\right] \mathrm{Cl}_{2}$ thin films on ITO-coated glass in the presence of chloride ions leads 
to photochemical loss of the photolabile pyridine (py) ligands, and sequential formation of poly- $\left[\mathrm{Ru}{ }^{\mathrm{II}}\left(\mathrm{L}^{1}\right)_{2}(\mathrm{py}) \mathrm{Cl}\right] \mathrm{Cl}$ and poly-[Ru $\left.{ }^{\mathrm{II}}\left(\mathrm{L}^{1}\right)_{2} \mathrm{Cl}_{2}\right]$. Contact lithography can be used to spatially control the photosubstitution process to form laterally resolved bicomponent films with image resolution below $10 \mu \mathrm{m}$. Dramatic changes occur in the colors and redox potentials of such ruthenium(II) complexes upon substitution of chloride for the pyridine ligands (figure 2). Striped patterns of variable colors are observed on addressing such films with a sequence of potentials.

FIGURE 2

\subsection{Oxidative Electropolymerization of Polypyridyl Complexes}

Oxidative electropolymerization of suitably substituted $\left[\mathrm{M}^{\mathrm{II}}(\text { bipy })_{3}\right]^{2+}$ complexes offers an alternative approach to the preparation of electrochromic redox active polymer films. Oxidative electropolymerization has been described for iron(II) and ruthenium(II) complexes containing amino- ${ }^{35}$ and pendant aniline- ${ }^{36}$ substituted $2,2^{\prime}$-bipyridyl ligands, and amino- and hydroxy- substituted 2,2':6' $2^{\prime \prime}$-terpyridinyl ligands ${ }^{37}$ (ligands $L^{4}$ and $L^{5}$ in figure 1 ). Analysis of IR spectra suggests that the electropolymerization of $\left[\mathrm{Ru}\left(\mathrm{L}^{4}\right)_{2}\right]^{2+}$, via the pendant aminophenyl substituent, proceeds by a reaction mechanism similar to that of aniline. ${ }^{37}$ The resulting metallopolymer film reversibly switches from purple to pale pink on oxidation of $\mathrm{Fe}(\mathrm{II})$ to $\mathrm{Fe}(\mathrm{III})$. For polymeric films formed from $\left[\mathrm{Ru}\left(\mathrm{L}^{5}\right)_{2}\right]^{2+}$ via polymerization of the pendant hydroxyphenyl group, the color switch is from brown to dark yellow. The dark yellow color is attributed to an absorption band at $455 \mathrm{~nm}$, probably due to quinone moieties in the polymer formed during electropolymerization. IR spectra confirm the absence of hydroxyl groups in the initially deposited brown films. 
Metallopolymer films have also been prepared by oxidative polymerization of complexes of the type $\left[\mathrm{M}(\text { phen })_{2}\left(4,4^{\prime} \text {-bipy }\right)_{2}\right]^{2+}(\mathrm{M}=\mathrm{Fe}, \mathrm{Ru}$, or Os; phen $=1,10$ phenanthroline, $4,4^{\prime}$-bipy $=4,4^{\prime}$-bipyridine) ${ }^{38}$ Such films are both oxidatively and reductively electrochromic; reversible film-based reduction at potentials below $-1.00 \mathrm{~V}$ leads to dark purple films, ${ }^{38}$ the color and potential region being consistent with the viologen dication/radical cation electrochromic response. A purple state at high negative potentials has also been observed for polymeric films prepared from $\left[\mathrm{Ru}\left(\mathrm{L}^{6}\right)_{3}\right]^{2+} \cdot{ }^{39}$ Electropolymerized films prepared from the complexes $\left[\mathrm{Ru}\left(\mathrm{L}^{7}\right)(\text { bipy })_{2}\right]\left[\mathrm{PF}_{6}\right]_{2}{ }^{40}$ and $\left[\mathrm{Ru}\left(\mathrm{L}^{8}\right)_{3}\right]\left[\mathrm{PF}_{6}\right]_{2}{ }^{41,42}$ exhibit reversible orange/transparent electrochromic behaviour associated with the $\mathrm{Ru}(\mathrm{II}) / \mathrm{Ru}(\mathrm{III})$ interconversion (see figure 1 for ligand structures).

\subsection{Metallophthalocyanine Electrochromic Films}

The porphyrins are a group of highly colored, naturally occurring pigments containing a porphine nucleus (figure 3 ) with substituents at the eight $\beta$-positions $(2,3,7,8,12,13,17,18)$ of the pyrroles, and/or the four meso-positions $(5,10,15,20)$ between the pyrrole rings. ${ }^{43}$ The natural pigments are metal chelate complexes of the porphyrins. Phthalocyanines (figure 3) are tetraazatetrabenzo derivatives of porphyrins with highly delocalised $\pi$-electron systems.

\section{FIGURE 3}

The metal ion in metallophthalocyanines lies either at the center of a single phthalocyanine ligand $(\mathrm{Pc}=$ dianion of phthalocyanine) (figure 3$)$, or between two rings in a sandwich-type complex. ${ }^{44}$ Phthalocyanine complexes of transition metals usually contain only a single Pc 
ring while lanthanide-containing species usually form bis(phthalocyanines), where the $\pi$ systems interact strongly with each other.

Since the discovery of the electrochromism of lutetium bis(phthalocyanine) $\left[\mathrm{Lu}(\mathrm{Pc})_{2}\right]$ thin films, ${ }^{2}$ the electrochromic properties of numerous (mainly rare-earth) metallophthalocyanines have been investigated. Lutetium bis(phthalocyanine) thin films are in fact polyelectrochromic, the initially deposited vivid green films being oxidized through a yellow-tan form, to a red form. Upon reduction, the green state can be switched first to a blue redox form, and then to a violet-blue form. ${ }^{2}$ Although, as described, $\left[\mathrm{Lu}(\mathrm{Pc})_{2}\right]$ films can exhibit five colors, only the blue-green transition is used in most prototype electrochromic devices. There are mechanical problems associated with the use of $\left[\mathrm{Lu}(\mathrm{Pc})_{2}\right]$-based films, but in spite of such difficulties, electrochromic displays with good reversibility, fast response times, and little degradation over $>5 \times 10^{6}$ cycles have been described.

The electrochromic properties of metallophthalocyanine films are generally investigated using low molecular weight sublimed (physical vapor deposition) films, ${ }^{44}$ although studies have also been carried out on films prepared using the Langmuir-Blodgett technique. ${ }^{44}$ More recently, methods for preparing thin films of polymeric phthalocyanines have been investigated. Such materials are attractive because of their rigidity, high stability and strong, well-defined coupling of the electronic $\pi$-systems. Because polymeric phthalocyanines are not soluble and cannot be vaporized, new methods of thin film formation have been developed. For complexes with pendant aniline and hydroxy-substituted ligands, oxidative electropolymerization is a useful route to the preparation of metallophthalocyanine electrochromic films. Although polymer films prepared from $\left[\mathrm{Lu}\left(\mathrm{L}^{9}\right)_{2}\right]\left(\mathrm{L}^{9}=4,4^{\prime}, 4^{\prime \prime}, 4^{\prime \prime \prime}-\right.$ tetraaminophthalocyanine) monomer show loss of electroactivity on cycling to positive potentials, in dimethyl sulfoxide (DMSO) the electrochemical response at negative potentials is stable, with the observation of two broad quasi-reversible one-electron redox couples. ${ }^{45}$ 
Spectroelectrochemical measurements reveal switching times of $<2$ s for the observed greengrey-blue color transitions in this region. The oxidative electropolymerization technique using pendant aniline substituents has also been applied to monophthalocyaninato transition metal complexes. ${ }^{46}$ Blue-green/yellow-brown/red-brown and green/blue/purple polyelectrochromism for cobalt and nickel complexes respectively, has been reported. The first reduction in the cobalt-based polymer is metal-centered, resulting in the appearance of a new MLCT transition, with the second reduction being ligand-centered. For the nickel-based polymer, in contrast, both redox processes are ligand-based.

Electrochromic polymer films have been prepared by oxidative electropolymerization of the monomer tetrakis(2-hydroxyphenoxy)phthalocyaninato cobalt(II). ${ }^{47}$ The technique involved voltammetric cycling at $100 \mathrm{mV} \mathrm{s}^{-1}$ from -0.2 to $+1.2 \mathrm{~V}$ vs. SCE in dry acetonitrile, resulting in the formation of a fine green polymer. Cyclic voltammograms during polymer growth showed the irreversible phenol oxidation peak at $+0.58 \mathrm{~V}$ and a reversible phthalocyanine ring oxidation peak at $+0.70 \mathrm{~V}$. Polymer-modified electrodes gave two distinct redox processes with half wave potentials at $-0.35[\mathrm{Co}(\mathrm{II}) / \mathrm{Co}(\mathrm{I})]$ and $-0.87 \mathrm{~V}$ (reduction of the ring). Color switching was from transparent light green [Co(II) state] to yellowish green [Co(I) state] to dark yellow (reduced ring).

Recently, the synthesis and electropolymerization of two tetrakis(2-pyrrol-1ylalkoxy)phthalocyanines has been reported, and the electrical and optical properties discussed. ${ }^{48}$ This is the first example of the electropolymerization of a phthalocyanine where the electropolymerizable group (pyrrole) is electronically isolated from the phthalocyanine.

A complementary ECD using plasma-polymerized ytterbium bis(phthalocyanine) (PP$\left.\mathrm{Yb}(\mathrm{Pc})_{2}\right)$ and thin films of the mixed-valence inorganic complex Prussian blue (PB, iron(III) hexacyanoferrate(II) films on ITO with an aqueous solution of $4 \mathrm{M} \mathrm{KCl}$ as electrolyte has been fabricated. ${ }^{49}$ Blue-to-green electrochromicity was achieved in a two-electrode cell by 
complementing the green-to-blue color transition (on reduction) of the $\mathrm{PP}-\mathrm{Yb}(\mathrm{Pc})_{2}$ film with the colorless (PW, Prussian white)-to-blue (PB) transition (oxidation) of the PB. A three-color display (blue, green and red) was fabricated in a three-electrode cell in which a third electrode (ITO) was electrically connected to the PB electrode. A reduction reaction at the third electrode, as an additional counter electrode, provided oxidation of the $\mathrm{PP}-\mathrm{Yb}(\mathrm{Pc})_{2}$ electrode, resulting in the red coloration of the $\mathrm{PP}-\mathrm{Yb}(\mathrm{Pc})_{2}$ film.

\section{Viologen Electrochromism and Polymeric Viologen Systems}

\subsection{Introduction}

Salts of quaternised 4,4'-bipyridine are herbicides and are manufactured on a large scale. ${ }^{15}$ The ready availability of $4,4^{\prime}$-bipyridine and the ease of varying the nature of the quaternising agent have allowed intensive research into the electrochromic properties of such 'viologens'. ${ }^{15}$ The prototype viologen, 1,1'-di-methyl-4,4'-bipyridilium, is known as methyl viologen (MV), with other simple symmetrical bipyridilium species being named 'substituent' viologen. Of the three common viologen redox states (figure 4), the dication is the most stable and is colorless when pure unless optical charge transfer with the counter anion occurs. Reductive electron transfer to the viologen dication forms the radical cation, the stability of which is attributable to the delocalisation of the radical electron throughout the $\pi$-framework of the bipyridyl nucleus, the 1 and $1^{\prime}$ substituents commonly bearing some of the charge.

\section{FIGURE 4}


The viologen radical cations are intensely colored, with high molar absorption coefficients, owing to optical charge transfer between the (formally) +1 and zero valent nitrogens.

Suitable choice of nitrogen substituents in viologens to attain the appropriate molecular orbital energy levels can, in principle, allow color choice of the radical cation. For example, alkyl groups, promote a blue/violet color whereas the radical cation of 1,1'-bis(4cyanophenyl)-4,4'-bipyridilium (cyanophenyl paraquat, ' $\mathrm{CPQ}$ ') ${ }^{50}$ in acetonitrile has an intense green color $\left(83,300 \mathrm{dm}^{3} \mathrm{~mol}^{-1} \mathrm{~cm}^{-1}\right.$ at the $\left.\lambda_{\max }(674 \mathrm{~nm})\right)$. The intensity of the color exhibited by di-reduced viologens (figure 4) is low since no optical charge transfer or internal transition corresponding to visible wavelengths is accessible.

The first electrochromic display using viologens was reported by Schoot et al. ${ }^{51}$ (of the Philips Laboratories) in 1973. Philips had submitted Dutch patents in $1970^{52}$ for $1,1^{\prime}$-diheptyl4,4'-bipyridilium as the electrochromic species, while in 1971 ICI patented the use of cyanophenyl paraquat. ${ }^{53}$ At this time, other displays based on heptyl viologen were being investigated by Barclay’s group at Independent Business Machines (IBM) ${ }^{54}$ and by Texas Instruments in Dallas, although their work was not published until after their programme was discontinued. ${ }^{55}$ A $64 \times 64$ pixel integrated display with 8 levels of grey tone on a 1-inch square silicon chip, capable of giving quite detailed images was reported. ${ }^{56}$ It is likely that these displays were not exploited further owing to LCD competition, although they may still have a size advantage in large area devices.

'Paper-quality' railway termini information long-term data displays are now close to commercialisation, using a new type of nano-structured electrochromic organic/inorganic hybrid system, where electrochromic groups such as phosphonated viologens and phenothiazine molecules are attached to the rough surface of a very high surface area porous oxide film. ${ }^{57,58}$ Typically, such films consist of networks of interconnected semi-conducting or conducting metal oxide nanocrystals, deposited onto an optically transparent conducting 
glass electrode. On applying a negative potential, electrons are injected into the conduction band of the semi-conductor and the absorbed molecule is reduced and changes color. Applying a positive potential reverses the process.

Whilst not a display device, it is of interest to note Gentex's commercialised automaticdimming interior 'Night Vision Safety' (NVS) mirror that employs viologen electrochromism. ${ }^{8}$ In this system, which functions wholly by solution electrochromism, an ITO-glass surface (conductive side inwards) and the reflective metallic surface, spaced a fraction of a millimetre apart, form the two electrodes of the cell, with a solvent containing two electroactive chemical species that function both as electrochromic materials and supporting electrolyte. The two electroactive chemical species comprise a substituted (cationic) viologen, which serves as the cathodic-colouring electrochromic species, and a negatively charged (possibly) phenylene diamine as the anodically colouring electrochromic material. After switching the mirror on, the species migrate to their respective electrodes. Once the dual electrochromic coloration process has begun, the products will diffuse away from their respective electrodes and meet in the intervening solution, where a mutual reaction regenerating the original uncoloured species takes place. This type of electrochromic device therefore requires application of a continuous small current for replenishment of the colored electroactive species lost by their mutual redox reaction in solution. Bleaching occurs at short or open circuit by homogeneous electron transfer in the bulk of the solution. Although not an electrochromic phenomenon, the ingenious control system for this device is noteworthy. A photosensitive detector is placed facing rearward to monitor any dazzling incident light. However, this would also be triggered in daylight, resulting in an unwanted darkening of the mirror. This problem is avoided by a second forward-looking detector, which, on seeing daylight, is programmed to cancel any operation of the controlling sensor, which therefore only responds at night. 


\subsection{Polymeric Viologen Systems}

The write-erase efficiency of an ECD using, for example, aqueous MV would be low since both the dicationic and radical-cation states are very soluble. Improved MV-based systems may be made by retarding the rate at which the radical-cation product of electron transfer diffuses away from the electrode by use of an anionic polyelectrolyte such as poly(2acrylamido-2-methylpropane-sulfonic acid (polyAMPS) ${ }^{59,60}$ or the sulfonated perfluorinated polyether, Nafion ${ }^{\circledR} \cdot{ }^{61,62}$ An alternative approach is the surface modification of an electrode using silanisation methodology ${ }^{63}$ a pre-formed polymeric viologen salt, ${ }^{64}$ or oxidative electropolymerization of a pyrrole-substituted viologen ${ }^{65}$ (figure 5) and a pyrroledisubstituted viologen, N, N'-bis (3-pyrrol-1-ylpropyl)-4,4'-bipyridilium. ${ }^{66,67}$

\section{FIGURE 5}

In a more recent approach, polyelectrolyte multilayers of poly(butanyl viologen) dibromide (PBV) and poly(styrene sulfonate) sodium salt (PSS) have been prepared ${ }^{68}$ using an $^{-}$ alternating polyion solution deposition technique. In this technique, the ITO substrate is alternatively exposed to positive and negative polyelectrolytes, with spontaneous polymer deposition via coulombic interactions between surface and polyion of opposite charge. In this 'layer-by-layer' deposition technique, all redox material is electrochemically addressable, with good electrochromic performance characteristics. 


\section{Conjugated Electrochromic Polymers}

\subsection{Introduction}

Chemical or electrochemical oxidation of numerous resonance-stabilised aromatic molecules, such as pyrrole, thiophene, aniline, furan, carbazole, azulene, indole, and others, produces electronically conducting polymers. ${ }^{2,17-19,69-71}$ The polymerization is believed to involve either radical-cation/radical-cation coupling or reaction of a radical-cation with a neutral monomer. The mechanism of electropolymerization of the five-membered heterocycle, pyrrole, with radical-cation/radical-cation coupling is shown in Figure 6.

\section{FIGURE 6}

After loss of two protons and re-aromatization, the dimer forms from the di-hydro dimer dication. The dimer (and succeeding oligomers) is more easily oxidized than the monomer and the resulting dimer radical cation undergoes further coupling reactions, proton loss and re-aromatization. Electropolymerization proceeds through successive electrochemical and chemical steps according to a general $\mathrm{E}(\mathrm{CE})_{\mathrm{n}}$ scheme, until the oligomers become insoluble in the electrolyte solution and precipitate onto the electrode surface. ${ }^{71}$ In this manner, high quality oxidized conducting films can be formed directly.

In the oxidized state, conducting polymers are charge balanced, 'doped', with counter anions ('p-doping') and have a delocalised $\pi$-electron band structure. ${ }^{71}$ Reduction of 'pdoped' conducting polymers, with concurrent counter anion exit (or electrolyte cation incorporation) removes the electronic conjugation to give the 'undoped' (neutral) electrically insulating form. The energy gap ( $E_{g}$, electronic bandgap) between the highest occupied $\pi$ - 
electron band (valence band) and the lowest unoccupied band (the conduction band) determines the intrinsic optical properties of these materials. This is illustrated in Figure 7 with polypyrrole once again as an example.

\section{FIGURE 7}

In some instances, the 'undoped' neutral state can undergo reductive cathodic 'doping', with cation insertion ('n-doping') to balance the injected charge. However, the stability of the negatively charged polymer state is limited and n-doping is more difficult to achieve. It is to be noted that the 'p-doping' and 'n-doping' nomenclature comes from classical semiconductor theory. The supposed similarity between conducting polymers and doped semiconductors arises from the manner in which the redox charges in the polymer change its optoelectronic properties. In fact, the suitability of the terms 'doping' and 'dopant' has been criticised when referring to the movement of counter ions and electronic charge through these polymers because true doping involves small (classically sub ppm) amounts of dopant. However, terms such as 'doping' are now so widely used that additional, new terminology might confuse.

All conducting polymers are potentially electrochromic, redox switching giving rise to new optical absorption bands in accompaniment with simultaneous transport of electronic charge and counter ions in the polymer matrix. Oxidative p-doping shifts the optical absorption band towards the lower energy part of the spectrum. The color change or contrast between doped and undoped forms of the polymer depends on the magnitude of the bandgap of the undoped polymer. Thin films of conducting polymers with $E_{g}$ greater than $3 \mathrm{eV}(\sim 400$ $\mathrm{nm})$ are colorless and transparent in the undoped form, while in the doped form they are generally absorbing in the visible region. Those with $\mathrm{E}_{\mathrm{g}}$ equal to or less than $1.5 \mathrm{eV}(\sim 800$ 
$\mathrm{nm}$ ) are highly absorbing in the undoped form but, after doping, the free carrier absorption is relatively weak in the visible region as it is transferred to the near infrared. Polymers with intermediate gaps have distinct optical changes throughout the visible region and can be made to induce many color changes.

\subsection{Thiophenes and Dioxythiophenes as Electrochromic Materials}

Polythiophenes ${ }^{71}$ are of interest as electrochromic materials due to their ease of chemical and electrochemical synthesis, environmental stability, and processability. A large number of substituted thiophenes has been synthesized, and this has led to the study of numerous novel polythiophene(s), with particular emphasis on poly(3-substituted thiophenes) and poly(3,4-disubstituted thiophenes). ${ }^{71}$ Thin polymeric films of the parent polythiophene are blue $\left(\lambda_{\max }=730 \mathrm{~nm}\right)$ in the doped (oxidized) state and red $\left(\lambda_{\max }=470 \mathrm{~nm}\right)$ in the undoped form. However, due to its lower oxidation potential, the electropolymerization and switching of 3-methylthiophene has been more intensively studied than the parent thiophene. Furthermore, the introduction of a methyl group at the $\beta$ position of the thiophene ring leads to a significant increase of the polymer conjugation length and hence electronic conductivity. ${ }^{71}$ This effect has been attributed to the statistical decrease in the number of $\alpha-\beta^{\prime}$ couplings and to the decrease of the oxidation potential caused by the inductive effect of the

methyl group. ${ }^{71}$ Poly(3-methylthiophene) is purple when neutral with an absorption maximum at $530 \mathrm{~nm}(2.34 \mathrm{eV})$ and turns pale blue on oxidation. ${ }^{72}$

The evolution of the electronic band structure during electrochemical p-doping of electrochromic polymers can be followed by recording in situ visible and NIR spectra. Figure 8 shows the spectroelectrochemical series for an alkylenedioxy-substituted thiophene polymer, poly(3,4-(ethylenedioxy)thiophene). The undoped polymer's strong absorption 
band, with a maximum at $621 \mathrm{~nm}(2.0 \mathrm{eV})$, is characteristic of a $\pi-\pi *$ interband transition. Upon doping, the interband transition decreases, and two new optical transitions (at $\sim 1.25$ and $\sim 0.80 \mathrm{eV}$ ) appear at lower energy, corresponding to the presence of a polaronic charge carrier (a single charge of $\operatorname{spin} 1 / 2$ ). Further oxidation leads to formation of a bipolaron and the absorption is enhanced at lower energies. The characteristic absorption pattern of the free carrier of the metallic-like state then appears when the bipolaron bands finally merge with the valence and conduction bands.

\section{FIGURE 8}

Tuning of color states is possible by suitable choice of thiophene monomer. This represents a major advantage of using conducting polymers for electrochromic applications. Subtle modifications to the monomer can significantly alter spectral properties. For example, the colors available with polymer films prepared from 3-methylthiophene-based oligomers are strongly dependent on the relative positions of methyl groups on the polymer backbone. ${ }^{72,73}$ Colors available include pale blue, blue and violet in the oxidized form, and purple, yellow, red and orange in the reduced form. The color variations have been ascribed to changes in the effective conjugation length of the polymer chain. Cast films of chemically polymerized thiophene-3-acetic acid reversibly switch from red to black on oxidation, demonstrating that subtle changes in structure can cause large effects in the colored states. ${ }^{74}$

Study of the effects of steric factors is provided by the electronic properties of polythiophenes with 3,4-dialkyl substituents. In principle, disubstitution at the $\beta$, $\beta^{\prime}$ positions should provide the synthetic basis to perfectly stereoregular polymers. However, this approach is severely limited by the steric interactions between substituents, which lead to a decrease in polymer conjugation length. In fact, poly(3,4-dialkylthiophenes) have higher 
oxidation potentials, higher optical bandgaps, and lower conductivities than poly(3alkylthiophenes). ${ }^{71}$ Cyclization between the 3 and 4 positions relieves steric hindrance in thiophenes, but many are harder to electropolymerize than, say, 3-methylthiophene. The electron-donating effect of alkoxy groups offers a solution here, and alkoxy-substituted polythiophenes are intensively investigated for their electrochromic properties. ${ }^{75,76}$

Materials based on poly(3, 4-(ethylenedioxy)thiophene) (PEDOT) have a bandgap lower than polythiophene and alkyl-substituted polythiophenes, owing to the presence of the two electron-donating oxygen atoms adjacent to the thiophene unit. As shown previously, the bandgap of PEDOT $\left(\mathrm{E}_{\mathrm{g}}=1.6-1.7 \mathrm{eV}\right)$ itself is $0.5 \mathrm{eV}$ lower than polythiophene, which results in an absorbance maximum in the red region of the electromagnetic spectrum. Compared to other substituted polythiophenes, these materials exhibit excellent stability in the doped state, which is associated with high conductivity. PEDOT was first developed by Bayer AG research laboratories in Germany in an attempt to produce an easily oxidized, soluble and stable conducting polymer. ${ }^{77,78}$ Bayer AG now produce the EDOT monomer, (3, 4(ethylenedioxy)thiophene), on a multi-ton scale and it is available commercially as BAYTRON M. To aid processing, the insolubility of PEDOT can be overcome by the use of a water soluble polyelectrolyte [poly(styrene sulfonate), PSS] as the counter ion in the doped state, to yield the commercially available product PEDOT:PSS (BAYTRON P by Bayer AG and Orgatron by AGFA Gevaert), which forms a dispersion in water

As PEDOT and its alkyl derivatives are cathodically coloring electrochromic materials, they are suitable for use with 'anodically-coloring' conducting polymers in the construction of dual polymer ECD's. ${ }^{79}$ Changes in the size of the alkylenedioxy ring and the nature of the substituents on the alkyl bridge have led to polymers with faster electrochromic switching, ${ }^{80-}$ ${ }^{82}$ higher optical contrasts, ${ }^{80-83}$ and better processability through increased solubility. ${ }^{84-87}$ 
Similar to polythiophenes, polypyrroles also have been extensively utilized as electrochromic materials and can be easily synthesized chemically or electrochemically with a varying range of optoelectronic properties available through alkyl and alkoxy substitution. Thin films of the parent polypyrrole are yellow/green $\left(\mathrm{E}_{\mathrm{g}} \sim 2.7 \mathrm{eV}\right)$ in the undoped insulating state and blue/violet in the doped conductive state. ${ }^{88}$ Polypyrroles exhibit lower oxidation potentials than their thiophene analogues ${ }^{89}$ and their enhanced compatibility in aqueous electrolytes have lead to interest for their use in biological systems. ${ }^{90}$

Similar to dialkoxy-substituted thiophenes, the addition of the oxygen at the 3 and 4 positions lowers the bandgap of the resulting polymer by raising the highest occupied molecular orbital (HOMO) level. This, combined with the already relatively low oxidation potential for polypyrrole, gives the poly(alkylenedioxypyrrole)s the lowest oxidation potential for p-type doping in conducting electrochromic polymers. ${ }^{91}$ Poly(3,4-(ethylenedioxy)pyrrole) (PEDOP) exhibits a bright red color in its neutral state and a light blue transmissive state upon oxidation and has a bandgap of $2.05 \mathrm{eV} ; 0.65 \mathrm{eV}$ lower than that of the parent pyrrole. ${ }^{92}$ Upon increasing the ring size of the alkyl bridge, another colored state is introduced at low doping levels. ${ }^{91}$ For poly(3,4-(propylenedioxy)pyrrole) (PProDOP), the neutral state is an orange color, passes through a brown color upon intermediate doping, and finally to a light gray/blue color upon full oxidation. ${ }^{91}$ This multichromism is also seen in the substituted PProDOPs and poly $\left(3,4-\left(\right.\right.$ butylenedioxy)pyrrole) (PBuDOP). ${ }^{91}$

The ability to perform substitution at the nitrogen in PXDOPs has allowed the creation of higher bandgap polymers while maintaining their low oxidation potentials. ${ }^{93}$ This substitution induces a twist in the polymer backbone, which results in a decrease of the effective $\pi$-conjugation, and an increase in the bandgap. This increase in the bandgap of the 
polymer results in the absorbance of the $\pi-\pi^{*}$ transition blue-shifted and the intragap polaron and bipolaron transitions occurring in the visible region. The nature of the substituent has an effect on the extent to which the $\pi-\pi^{*}$ transition is shifted. For $N$-methyl PProDOP the bandgap occurs at $3.0 \mathrm{eV}$, compared to $2.2 \mathrm{eV}$ for PProDOP, and has a purple color in the neutral state and is blue when fully oxidized passing through a dark green color at intermediate oxidation levels. ${ }^{93}$ Both $N$-[2-(2-Ethoxy-ethoxy)-ethyl] PProDOP (N-Gly PProDOP) and $N$-propanesulfonate PProDOP ( $N$-PrS PProDOP) are colorless when fully reduced and colored upon full oxidation. ${ }^{93}$ Both polymers also exhibit multiple colored states at intermediate oxidation levels. ${ }^{93}$ These two polymers are what are referred to as anodically coloring polymers in that they change from a colorless state to a colored one upon oxidation as opposed to cathodically coloring polymers that are colored in their reduced state and become colorless upon oxidation. These $N$-substituted polymers have been shown to work effectively in dual polymer high-contrast absorptive/transmissive electrochromic devices as the anodically coloring material due to their electrochemical and optical compatibility with various PXDOT polymers. $^{94}$

\subsection{Copolymers and n-Dopable Electrochromic Polymers}

As for thiophene, many substituted EDOT monomers have been synthesized, and this has led to the study of a range of variable-bandgap PEDOT-based materials. ${ }^{75,76}$ The bandgap of such conjugated polymers is controlled by varying the degree of $\pi$-overlap along the backbone via steric interactions, and by controlling the electronic character of the $\pi$-system with electron-donating or accepting substituents. The latter is accomplished by using substituents and co-repeat units that adjust the highest occupied molecular orbital (HOMO) and lowest unoccupied molecular orbital (LUMO) energy levels of the $\pi$-system. ${ }^{75,76}$ An 
interesting set of materials is the family of EDOT-based polymers that has been prepared with higher energy gaps than the parent PEDOT. Using a series of oxidatively polymerizable bisarylene EDOT monomers (figure 9), polymers with bandgaps ranging from $1.4-2.5 \mathrm{eV}$ have been prepared that exhibit two to three distinct colored states. ${ }^{75,76,95-97}$

\section{FIGURE 9}

In the neutral polymers, a full 'rainbow' of colors is available, from blue through purple, red, orange, green, and yellow as seen in Figure 10. A few examples include bisarylene EDOT-based polymers, with spacers of vinylene $\left(\mathrm{E}_{\mathrm{g}}=1.4 \mathrm{eV}\right)$ that has a deep purple neutral state, biphenyl $\left(\mathrm{E}_{\mathrm{g}}=2.3 \mathrm{eV}\right)$ that is orange, $p$-phenylene $\left(\mathrm{E}_{\mathrm{g}}=1.8\right)$ that is red, and carbazole $\left(\mathrm{E}_{\mathrm{g}}=2.5 \mathrm{eV}\right)$ that is yellow. ${ }^{95,96}$

\section{FIGURE 10}

The ability to tune the color of the neutral polymer by control over the comonomer concentration during electrochemical copolymerization has also been shown utilizing the monomers EDOT and BEDOT-NMeCz. ${ }^{98}$ As shown in Figure 11, by varying the ratios of comonomer concentrations, colors ranging from yellow to red to blue can be reached in the neutral polymer film. ${ }^{98}$ In all copolymer compositions, the films pass through a green intermediate state to a blue fully oxidized state. ${ }^{98}$

FIGURE 11 
As mentioned previously, some electrochromic polymers also exhibit n-type doping. Although n-type doping in most of these polymers is inherently instable to water and oxygen, the introduction of donor-acceptor units has shown to increase the stability of this n-type redox state. While incorporation of an electron-rich donor unit allows oxidation for p-doping, the mutual use of an electron-poor acceptor unit allows for reduction. This has been shown with EDOT acting as the donor unit and both pyridine (Pyr) and pyrido[3,4-b] pyrazine $\left(\operatorname{PyrPyr}(\mathrm{Ph})_{2}\right)$ as the acceptor unit. ${ }^{99,100}$ PBEDOT-Pyr shows a red color in the neutral state, upon p-doping changes to a light blue, and changes to a blue upon n-doping. ${ }^{99,100}$ PBEDOT$\operatorname{Pyr} \operatorname{Pyr}(\mathrm{Ph})_{2}$ is green when neutral, grey upon p-doping, and magenta upon n-doping. ${ }^{99,100}$

A model ECD using poly(cyclopenta[2,1 -b; 4,3-b']dithiophen-4(cyano,nonafluorobutylsulfonyl)-methylidene) (PCNFBS), a low bandgap conducting polymer that is both p- and n-dopable, as both the anode and the cathode material has been reported. ${ }^{101}$ PCNFBS is one of a series of fused bithiophene polymers whose $\mathrm{E}_{\mathrm{g}}$ values can be controlled by addition of electron-withdrawing substituents. Electrochemically polymerized films of the polymer switch from red in the neutral state to purple in both the $\mathrm{p}$ - and $\mathrm{n}$-doped states. ${ }^{101}$ The spectral changes observed in the an electrochemical cell assembled from two polymer-coated transparent electrodes, utilized to model an ECD, were a combination of those seen in the separate $\mathrm{p}$ - and n-doped films. ${ }^{101}$

\subsection{Functionalized Electrochromic Polymers and Composites}

Following earlier work ${ }^{68}$ with polyviologen systems, the layer-by-layer deposition of PEDOT:PSS (as the polyanion) with linear poly(ethylene imine) (LPEI) (as the polycation) has recently been reported. ${ }^{102}$ The PEDOT:PSS/LPEI (cathodically coloring) electrode was then combined with a polyaniline/polyAMPS (anodically coloring) layered system to give a 
blue-green to yellow electrochromic device. More recently, the redox and electrochromic properties of films prepared by the layer-by-layer deposition of fully water soluble, self-doped poly(4-(2,3-dihydrothieno [3,4-b]-[1,4]dioxin-2-yl-methoxy)-1-butanesulfonic acid, sodium salt (PEDOT-S) and poly(allylamine hydrochloride) (PAH) onto unmodified ITO-coated glass have been studied. ${ }^{103}$ PEDOT-S is a self-doping polymer where oxidation and reduction of the polymer backbone is coupled with cation movement out of (oxidized) and back into (reduced) the polymer film. For this system, both the film preparation and redox switching is carried out in an aqueous medium. The PEDOT-S/PAH film was found to switch from light blue, in the oxidized form to pink/purple in the reduced form.

'Star' conducting polymers, which have a central core with multiple branching points and linear conjugated polymeric arms radiating outward, are currently being investigated for electrochromic applications. ${ }^{104-107}$ Examples include star conducting polymers in which the centrosymmetric cores include hyperbranched poly(1,3,5-phenylene) (PP) and poly(triphenylamine) (PTPA) and the radiating arms are regioregular poly(3hexylthiophene), poly(3,4-(ethylenedioxy)thiophene-didodecyloxybenzene) and poly(dibutyl3,4-(propylenedioxy)thiophene). ${ }^{104-107}$ These polymers have the advantage that they can be spin coated from a carrier solvent such as tetrahydrofuran (THF), and several can be doped in solution, so that thin films of both doped and undoped forms can be prepared. Despite the branched structure, star polymers self-assemble into thin films with morphological, electrical, and optical properties that reveal a surprisingly high degree of structural order. The polymers, which are smooth and reflective, all have spectral features that produce a strong band in the visible region for the reduced state and a broad band extending into the NIR for the oxidized state. The color of the polymers ranges from red to violet to deep blue in the reduced state, and blue to very pale blue in the oxidized state. 
A new organic/inorganic complementary ECD has recently been described, ${ }^{108}$ based on the assembly of PEDOT/ITO glass and Prussian blue (PB, iron(III) hexacyanoferrate(II))/ITO glass substrates with a poly(methyl methacrylate) (PMMA)-based gel polymer electrolyte. The color states of the PEDOT (blue/colorless) and PB (colorless/blue) films fulfill the complementary requirement. Similarly, numerous workers ${ }^{109-116}$ have combined Prussian blue with polyaniline in complementary ECDs that exhibit deep blue-to-light green electrochromism. Electrochromic compatibility is obtained by combining the colored oxidized state of the polymer with the blue of $\mathrm{PB}$, and the 'bleached' reduced state of the polymer with Prussian green (PG). An electrochromic window for solar modulation using PB, polyaniline and $\mathrm{WO}_{3}$ has been developed, ${ }^{112,113,115,116}$ where the symbiotic relationship between polyaniline and PB was exploited in a complete solid-state electrochromic window. Compared to earlier results with a polyaniline/ $\mathrm{WO}_{3}$ window, much more light was blocked off by inclusion of $\mathrm{PB}$ within the polyaniline matrix, while still regaining about the same transparency during the bleaching of the window. Other polyaniline-based ECDs include a device that exhibits electrochromicity using electropolymerized 1, $1^{\prime}$-bis $[[p-$ phenylamino(phenyl)]amido-]ferrocene. ${ }^{117}$ The monomer consists of a ferrocene group and two flanking polymerizable diphenylamine endgroups linked to the ferrocene by an amide bond. A solid-state aqueous-based ECD was constructed utilizing this polymer as the electrochromic material in which the polymer switched from a yellow neutral state to blue upon oxidation. ${ }^{117}$

The electropolymerization of monomers in the presence of other electrochromic additives which may have electrochromic or other properties has been a popular approach to the preparation of materials with tailored properties. ${ }^{2}$ A water-soluble poly(styrenesulfonic acid)-doped polyaniline has been prepared both by persulfate oxidative coupling and anodic oxidation of aniline in aqueous dialysed poly(styrene sulfonic acid) solution. ${ }^{118}$ Composites of 
polyaniline and cellulose acetate have been prepared both by casting of films from a suspension of polyaniline in a cellulose acetate solution and deposition of cellulose acetate films onto electrochemically prepared polyaniline films. ${ }^{119}$ The electrochromic properties of the latter films were studied by spectroelectrochemistry and the presence of the cellulose acetate was found not to impede the redox processes of the polyaniline. The electroactivity and electrochromism of the graft copolymer of polyaniline and nitrilic rubber have been studied using stress-strain measurements, cyclic voltammetry, frequency response analysis and visible range spectroelectrochemistry. ${ }^{120}$ Results indicated that the graft copolymer exhibits mechanical properties similar to a crosslinked elastomer with the electrochromic and electrochemical properties typical of polyaniline.

An example of a case where the additive itself is electrochromic is the encapsulation of the redox indicator dye indigo carmine within a polypyrrole matrix. ${ }^{121,122}$ The enhancement and modulation of the color change on indigo carmine insertion into polypyrrole or polypyrrole/dodecylsulfonate films was shown. ${ }^{123}$ As expected, the use of indigo carmine as dopant improves the films' electrochromic contrast ratio.

\subsection{Polyanilines as Electrochromic Materials}

Polyaniline films are polyelectrochromic (yellow-green-dark blue-black), ${ }^{124}$ the yellowgreen transition being durable to repetitive color switching even though the leucomeraldine form is not fully conjugated. ${ }^{125}$ Several redox mechanisms involving protonation-

deprotonation and/or anion ingress/egress have been proposed, ${ }^{126-128}$ with Figure 12 giving the composition of the various redox states.

FIGURE 12 
The electrochemistry of polyaniline has been shown to be that of a two step oxidation with radical cations as intermediates. At lower applied potentials, the absorbances of polyaniline films at 430 and $810 \mathrm{~nm}$ are enhanced as the applied potential increases in a more positive direction. ${ }^{129}$ At higher applied potentials, the absorbance at $430 \mathrm{~nm}$ begins to decrease while the wavelength of maximum absorbance shifts from $810 \mathrm{~nm}$ to wavelength of higher energies. $^{129}$

Of the numerous conducting polymers based on substituted anilines that have been investigated, those with alkyl substituents have received much attention. Poly(o-toluidine) and poly(m-toluidine) films have been found to offer enhanced stability of polyelectrochromic response in comparison with polyaniline. ${ }^{130}$ Absorption maxima and redox potentials shift from values found for polyaniline due to the lower conjugation length in polytoluidines. Response times, $\tau$, for the yellow-green electrochromic transition in the films correlate with the likely differences in the conjugation length implied from the spectroelectrochemical data. $\tau$ values for polyaniline are found to be lower than for poly(o-toluidine), which in turn has lower values than poly(m-toluidine). As for polyaniline, response times indicate that the reduction process is faster than the oxidation. Electrochemical quartz crystal microbalance (EQCM) studies have demonstrated the complexity of redox switching in poly(o-toluidine) films in aqueous perchloric acid solutions which occurs in two stages and is accompanied by non-monotonic mass changes that are the result of perchlorate counter ion, proton co-ion, and solvent transfers. ${ }^{131}$ The extent and rate of each of these transfers are dependent upon electrolyte concentration, experimental time scale, and the switching potential, so that observations in a single electrolyte on a fixed time scale cannot be unambiguously interpreted. While electropolymerization is a suitable method for the preparation of relatively low surface area electrochromic conducting polymer films, it may not be suitable for fabricating large-area coatings. As noted above for PEDOT materials, significant effort therefore goes 
into the synthesis of soluble conducting polymers, such as poly(o-methoxyaniline), which can then be deposited as thin films by casting from solution. In a novel approach, large-area electrochromic coatings have been prepared by incorporating polyaniline into polyacrylatesilica hybrid sol-gel networks using suspended particles or solutions and then spray or brushcoating onto ITO surfaces. ${ }^{132}$ Silane functional groups on the polyacrylate chain act as coupling and cross-linking agents to improve surface adhesion and mechanical properties of the resulting composite coatings.

\section{Conclusions}

The field of electrochromism is rapidly expanding both in terms of the range of electrochromic systems that has been reported and the novel commercial applications that are being proposed. In the case of organic and polymeric electrochromic materials for display applications, a number of representative examples have been described in this article. Tailoring the color of electrochromic polymers remains a particularly active research area. Although not described here, in addition to the synthesis of novel functionalized monomers and use of composites, other chemical and physical methods are investigated for the control of the perceived color of electrochromic polymers. Methods include the use of polymer blends, laminates and patterning using screen and ink-jet printing. ${ }^{135}$ Analysis of ECD color changes are now routinely measured by spectrocolorimetry using Commission Internationale de l'Eclairage (CIE) (x,y)-chromaticity coordinates. This method is useful for the comparison of the electrochemical and optical properties of conjugated polymers, and for gaining control

of the color of dual polymer electrochromic devices. ${ }^{136,137}$ By controlling the electron density and steric interactions along conjugated polymer backbones, a set of electrochromic polymers 
that provide colors through the full range of color space have been developed through the study of twelve electrochromic polymers. ${ }^{136}$

\section{Acknowledgements}

We thank the EPSRC for an Overseas Travel Grant (GR/T23886/01) to RJM and the AFOSR (F49620-03-1-0091) for financial support. 
Figure 1

Some vinyl-substituted pyridyl ligands that are used to prepared transition metal complexes for oxidative electropolymerization studies.

$L^{1}$<smiles>C=Cc1ccncc1</smiles><smiles>Nc1cccc(-c2cc(-c3ccccn3)nc(-c3ccccn3)c2)c1</smiles>

$L^{7}$

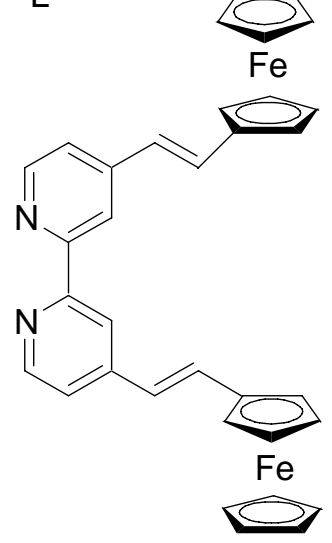

$\mathrm{L}^{2}$<smiles>C=Cc1ccnc(-c2cc(C)ccn2)c1</smiles>

$L^{5}$<smiles>Oc1ccccc1-c1cc(-c2ccccn2)nc(-c2ccccn2)c1</smiles>

$L^{8}$<smiles>COc1ccc(/C=C/c2ccnc(-c3cc(C)ccn3)c2)cc1OC</smiles> 


\section{Figure 2}

Spatial electrochromism in metallopolymeric films using photolabile pyridine ligands.

poly $\left[\mathrm{Ru}^{\prime \prime}\left(\mathrm{L}^{1}\right)_{2}(\mathrm{py})_{2}\right] \mathrm{Cl}_{2}$ (orange) $\quad \mathrm{E}_{\mathrm{f}}\left(\mathrm{Ru} \mathrm{u}^{\mathrm{III/I}}\right)=+1.27 \mathrm{~V}$ vs. SCE

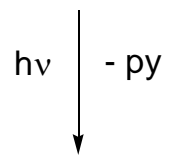

poly $\left[\mathrm{Ru}^{\prime \prime}\left(\mathrm{L}^{1}\right)_{2}(\mathrm{py}) \mathrm{Cl}\right] \mathrm{Cl}$ (red) $\quad \mathrm{E}_{\mathrm{f}}\left(\mathrm{Ru}^{\mathrm{III} / \mathrm{II}}\right)=+0.77 \mathrm{~V}$ vs. SCE

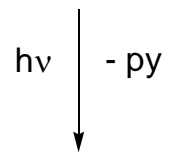

poly $\left[\mathrm{Ru}^{\prime \prime}\left(\mathrm{L}^{1}\right)_{2} \mathrm{Cl}_{2}\right]$ (purple) $\quad \mathrm{E}_{\mathrm{f}}\left(\mathrm{Ru}^{\mathrm{III} / \mathrm{ll}}\right)=+0.35 \mathrm{~V}$ vs. SCE 


\section{Figure 3}

Structures of a selection of porphyrins and phthalocyanines.

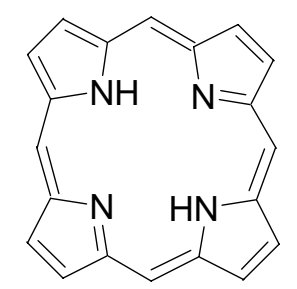

$21 \mathrm{H}, 23 \mathrm{H}$-porphyrin



$29 \mathrm{H}, 31 \mathrm{H}$-phthalocyanine



Tetraphenyl porphyrin (TPP)

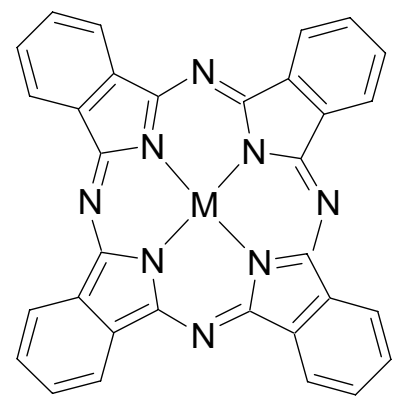

A 1:1 metallo-phthalocyanine complex 
Figure 4

The three common redox states of viologens, showing the two successive electron transfer reactions.<smiles>[R]N1C=CC(=C2C=CN([R])C=C2)C=C1</smiles> 
Figure 5

Modified viologens used for surface modification.<smiles>CO[SiH2]c1ccc(C[n+]2ccc(-c3cc[n+](Cc4ccc([SiH](C)C)cc4)cc3)cc2)cc1</smiles><smiles>CCC(C)c1ccc(S(=O)(=O)[O-])cc1</smiles>

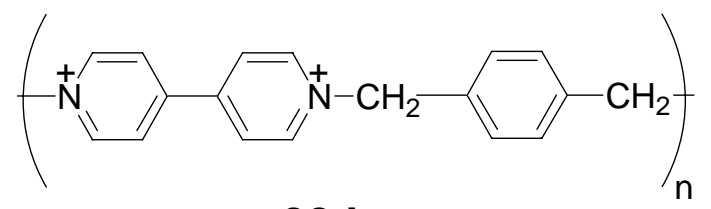<smiles>CC(C)Cc1ccc(S(=O)(=O)[O-])cc1</smiles><smiles>C[n+]1ccc(-c2cc[n+](Cn3cccc3)cc2)cc1</smiles> 
Figure 6

Proposed mechanism of electropolymerization of pyrrole. The case of radical-cation/radicalcation coupling is shown.


etc.

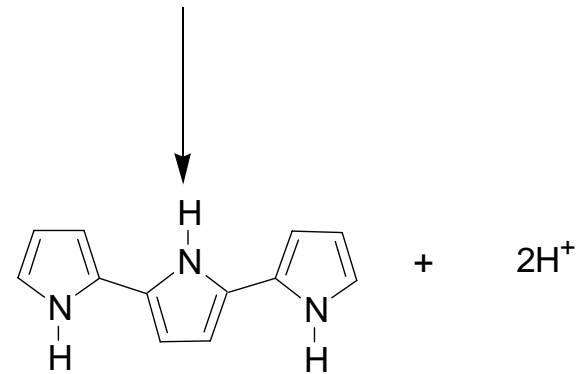




\section{Figure 7}

Electrochromism in polypyrrole thin films. The yellow-green (undoped) form undergoes reversible oxidation to the blue-violet (conductive) form, with insertion of chargecompensating anions $\left(\mathrm{X}^{-}\right)$.

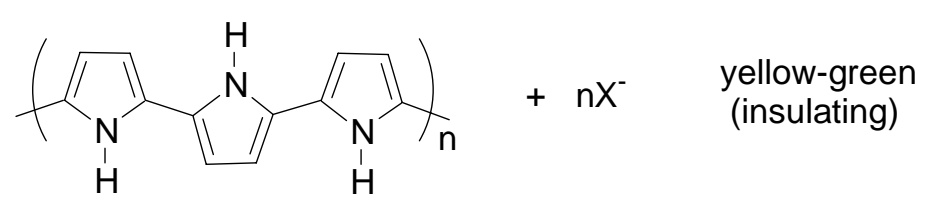
undoping $\|$ p-doping

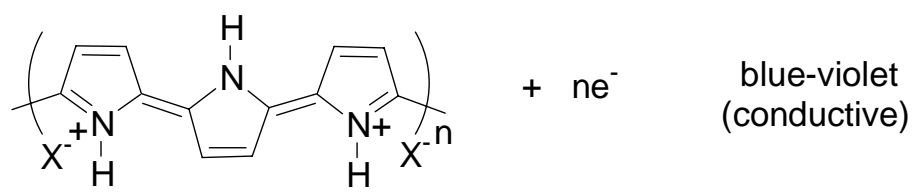


Figure 8

Spectroelectrochemistry for PEDOT film on ITO. Reprinted with permission from ref 133.

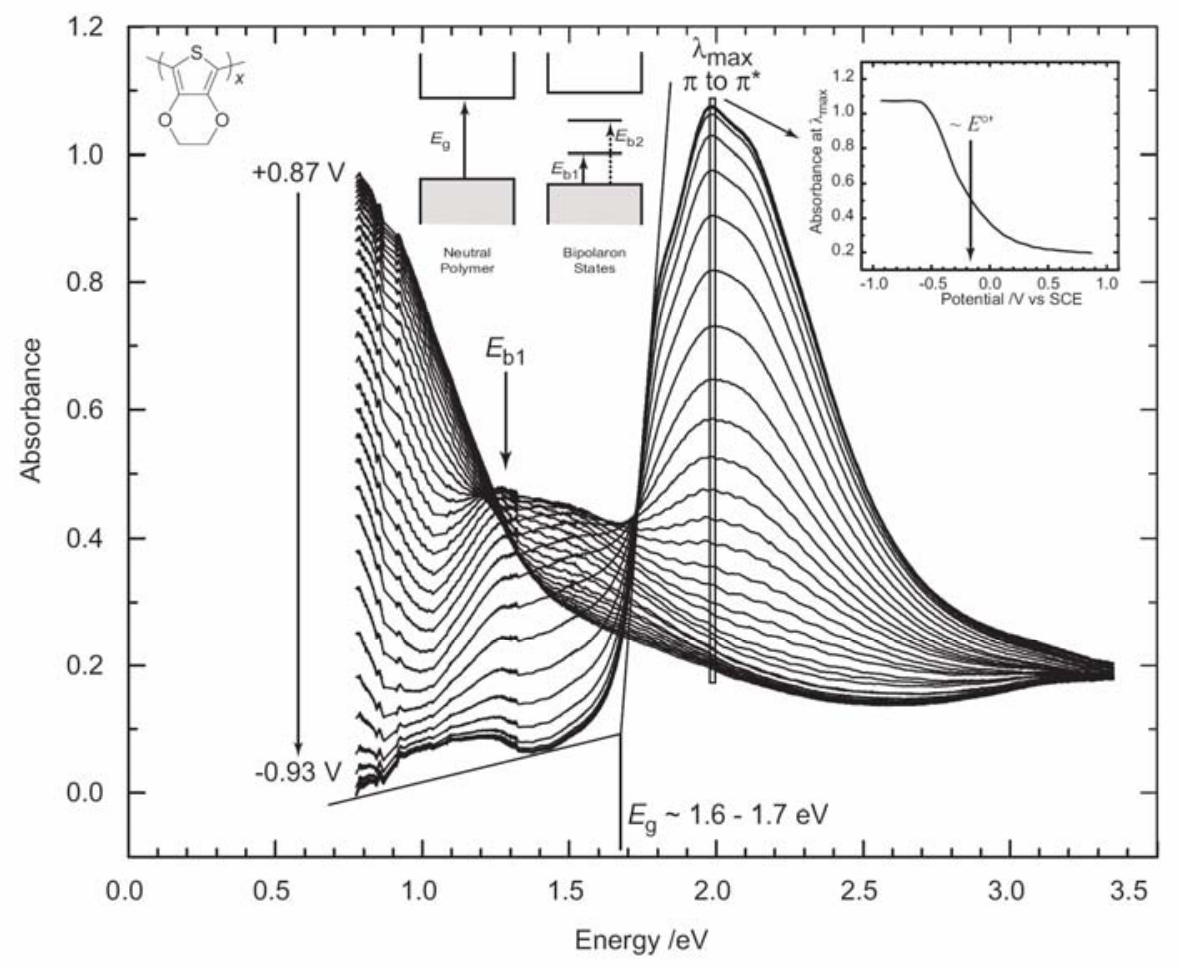


Figure 9

Bis-EDOT-arylene co-oligomers.




Figure 10

Photograph of a series of neutral EDOT and BEDOT-arylene variable color electrochromic polymer films on ITO/glass illustrating range of colors available. Reprinted with permission from ref. 134

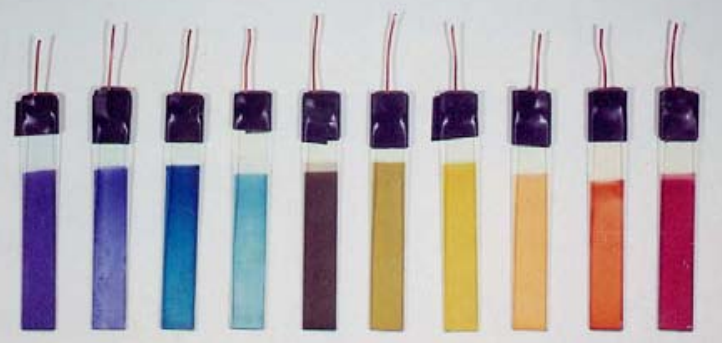


Figure 11. Representative Copolymer Structure and Electrochromic Properties of

Electrochemically Prepared Copolymers of Varied Compositions. Reprinted with permission from ref. 98.

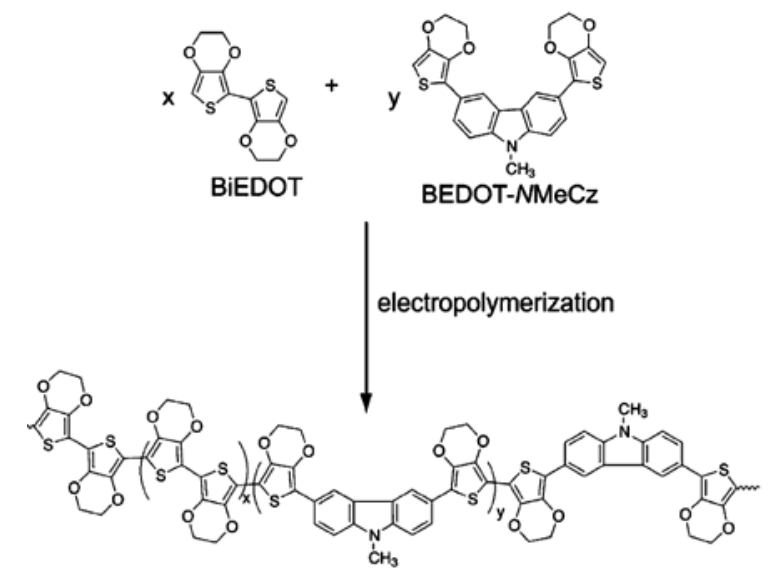

\begin{tabular}{ccc}
\hline $\begin{array}{c}\text { Comonomer Solution } \\
\text { Composition }\end{array}$ & $\begin{array}{c}\text { Neutral Polymer } \lambda_{\max } \\
(\mathrm{nm})\end{array}$ & $\begin{array}{c}\text { Neutral Electrochromic } \\
\text { Response (Photograph) }\end{array}$ \\
\hline $100 \%$ BiEDOT & 577 & \\
$90: 10$ & 559 & \\
$80: 20$ & 530 & \\
$70: 30$ & 464 & \\
$50: 50$ & 434 & \\
$30: 70$ & 431 & \\
$20: 80$ & 429 & \\
$10: 90$ & 420 & \\
$100 \%$ BEDOT- $\mathrm{NMeCz}$ & 420 & \\
\hline
\end{tabular}


Figure 12

Proposed composition of some of the redox states of polyaniline, from the fully reduced (leucoemeraldine) through to the fully oxidised (pernigraniline) forms. $\mathrm{X}^{-}$is a chargebalancing anion.<smiles>CCc1ccc(Nc2ccc(Nc3ccc(Nc4ccc(Nc5ccc(CC)cc5)cc4)cc3)cc2)cc1</smiles><smiles>[X]c1ccc(N([Y])c2ccc(Nc3ccc(Nc4ccc(CC)cc4)cc3)cc2)cc1</smiles><smiles>Cc1ccc(Nc2ccc(Nc3ccc(N=C4C=CC(=Nc5ccccc5)C=C4)cc3)cc2)cc1</smiles>
blue (emeraldine base)<smiles>CN=C1C=CC(=Nc2ccc(N=C3C=CC(=Nc4ccc(C)cc4)C=C3)cc2)C=C1</smiles> 


\section{References}

${ }^{1}$ P. Bamfield, Chromic Phenomena: Technological Applications of Colour Chemistry, Royal Society of Chemistry, Cambridge, 2001.

${ }^{2}$ P.M.S. Monk, R.J. Mortimer, D.R. Rosseinsky, Electrochromism: Fundamentals and Applications, VCH, Weinheim, 1995.

${ }^{3}$ C.G. Granqvist, Handbook of Inorganic Electrochromic Materials, Elsevier, Amsterdam, 1995.

${ }^{4}$ M. Green, The promise of electrochromic systems, Chem. Ind. (1996) 641-644.

${ }^{5}$ N. Leventis, Electrochromic devices, in McGraw-Hill Encyclopedia of Science and Technology, 9th Ed., McGraw-Hill, New York, 6 (2002) 254-257.

${ }^{6}$ R.J. Mortimer, Electrochromic materials, Chem. Soc. Rev. 26 (1997) 147-156.

${ }^{7}$ R.J. Mortimer, Organic electrochromic materials, Electrochim. Acta 44 (1999) 2971-2981.

${ }^{8}$ D.R. Rosseinsky, R.J. Mortimer, Electrochromic systems and the prospects for devices, Adv. Mater. 13 (2001) 783-793.

${ }^{9}$ N.M. Rowley, R.J. Mortimer, New electrochromic materials, Science Progress 85 (2002) $243-262$

${ }^{10}$ R.J. Mortimer, N.M. Rowley, Metal complexes as dyes for optical data storage and electrochromic materials, in J.A. McCleverty, T.J. Meyer, eds., Comprehensive Coordination Chemistry - II: From Biology to Nanotechnology, Elsevier, Oxford, Volume 9.2, M.D. Ward, ed., pp. 581-619, (2004).

${ }^{11}$ R.D. Rauh, Electrochromic windows: an overview, Electrochim. Acta 44 (1999) 31653176.

${ }^{12}$ M.D. Ward, J.A. McCleverty, Non-innocent behaviour in mononuclear and polynuclear complexes: consequences for redox and electronic spectroscopic properties, J. Chem. Soc. Dalton Trans. (2002) 275-288. 
${ }^{13}$ Z.C. Wu, Z.H. Chen, X. Du, J.M. Logan, J. Sippel, M. Nikolou, K. Kamaras, J.R.

Reynolds, D.B. Tanner, A.F. Hebard, A.G. Rinzler, Transparent, conductive carbon nanotube films, Science 305 (2004) 1273-1276.

${ }^{14}$ R.A. Colley, P.M. Budd, J.R. Owen, S. Balderson, Poly[oxymethylene-oligo(oxyethylene)] for use in subambient temperature electrochromic devices, Polym. Int. 49 (2000) 371-376.

${ }^{15}$ P.M.S. Monk, The Viologens: Physicochemical Properties, Synthesis and Applications of the Salts of 4,4'-Bipyridine, J. Wiley \& Sons, Chichester, 1998.

${ }^{16}$ T.A. Skotheim, R.L. Elsenbaumer, J.R. Reynolds, eds., Handbook of Conducting Polymers, 2nd Ed., Marcel Dekker, New York, (1998).

${ }^{17}$ J. Heinze, Electronically conducting polymers, Top. Curr. Chem. 152 (1990) 1-47.

${ }^{18}$ S.J. Higgins, Conjugated polymers incorporating pendant functional groups - synthesis and characterisation, Chem. Soc. Rev. 26 (1997) 247-257.

${ }^{19}$ M. Mastragostino, Electrochromic Devices, in B. Scrosati, ed., Applications of

Electroactive Polymers, Chapman and Hall, London (1993), ch. 7, pp. 223-249.

${ }^{20}$ B. Scrosati, Laminated Electrochromic Displays and Windows, in B. Scrosati, ed., Applications of Electroactive Polymers, Chapman and Hall, London (1993), ch. 8, pp. 250282.

${ }^{21}$ J.N. Huiberts, R. Griessen, J.H. Rector, R.J. Wijngarden, J.P. Decker, D.G. de Groot, N.J. Koeman, Yttrium and lanthanum hydride films with switchable optical properties, Nature 380 (1996) 231-234.

${ }^{22}$ Electrochemical Methods: Fundamentals and Applications, 2nd Ed., A.J. Bard, L.R. Faulkner, J. Wiley \& Sons, New York, 2001.

${ }^{23}$ R.J. Mortimer, Electronic Spectroscopy: Spectroelectrochemistry, Applications, in J.C. Lindon, G.E. Tranter, J.L. Holmes, eds., Encyclopedia of Spectroscopy and Spectrometry, Academic Press, London, 3 (1999) 2161-2174. 
${ }^{24}$ R.J. Mortimer, Electronic Spectroscopy: Spectroelectrochemistry, Methods and Instrumentation, in J.C. Lindon, G.E. Tranter, J.L. Holmes, eds., Encyclopedia of Spectroscopy and Spectrometry, Academic Press, London, 3 (1999) 2174-2181.

${ }^{25}$ A.A. Argun, A. Cirpan, J.R. Reynolds, The first truly all-polymer electrochromic devices, Adv. Mater. 15 (2003) 1338-1341.

${ }^{26}$ A.A. Argun, P-H. Aubert, B.C. Thompson, I. Schwendeman, C.L. Gaupp, J. Hwang, N.J. Pinto, D.B. Tanner, A.G. MacDiarmid, J.R. Reynolds, Multi-colored electrochromism in polymers: structures and devices, Chem. Mater. 16 (2004) 4401-4412.

${ }^{27}$ A.A. Argun, J.R. Reynolds, Line patterning for flexible and laterally configured electrochromic devices, J. Mater.Chem. Submitted.

${ }^{28}$ A.A. Argun, M. Berard, P-H. Aubert, J.R. Reynolds, Back-side electrical contacts for patterned electrochromic devices on porous substrates, Adv. Mater. In press.

${ }^{29}$ P-H. Aubert, A.A. Argun, A. Cirpan, D.B. Tanner, J.R. Reynolds, Microporous patterned electrodes for color-matched electrochromic polymer displays, Chem. Mater. 16 (2004) 23862393.

${ }^{30}$ A. Juris, V. Balzani, F. Barigelletti, S. Campagna, P. Belser, A. von Zelewsky, Ru(II)polypyridine complexes - photophysics, photochemistry, electrochemistry and chemiluminescence, Coord. Chem. Rev. 84 (1988) 85-277.

${ }^{31}$ R.J. Mortimer, Dynamic processes in polymer modified electrodes, in R.G. Compton, G. Hancock, eds., Research in Chemical Kinetics, Elsevier, Amsterdam, 2 (1994) 261-311. ${ }^{32}$ H.D. Abruña, P. Denisevich, M. Umaña, T.J. Meyer, R.W. Murray, Rectifying interfaces using 2-layer films of electrochemically polymerized vinylpyridine and vinylbipyridine complexes of ruthenium and iron on electrodes, J. Am. Chem. Soc. 103 (1981) 1-5. 
${ }^{33}$ S. Gould, G.F. Strouse, T.J. Meyer, B.P. Sullivan, Formation of thin polymeric films by electropolymerization - reduction of metal-complexes containing bromomethyl-substituted derivatives of 2,2'-bipyridine, Inorg. Chem. 30 (1991) 2942-2949.

${ }^{34}$ R.M. Leasure, W. Ou, J.A. Moss, R.W. Linton, T.J. Meyer, Spatial electrochromism in metallopolymeric films of ruthenium polypyridyl complexes, Chem. Mater. 8 (1996) 264-273. ${ }^{35}$ C.D. Ellis, L.D. Margerum, R.W. Murray, T.J. Meyer, Oxidative electropolymerization of polypyridyl complexes of ruthenium, Inorg. Chem. 22 (1983) 1283-1291.

${ }^{36}$ C.P. Horwitz, Q. Zuo, Oxidative electropolymerization of iron and ruthenium complexes containing aniline-substituted 2,2'-bipyridine ligands, Inorg. Chem. 31 (1992) 1607-1613.

${ }^{37}$ K. Hanabusa, A. Nakamura, T. Koyama, H. Shirai, Electropolymerization and characterization of terpyridinyl iron(II) and ruthenium(II) complexes, Polym. Int. 35 (1994) 231-238.

${ }^{38}$ H-T. Zhang, P. Subramanian, O. Fussa-Rydal, J.C. Bebel, J.T. Hupp, Electrochromic devices based on thin metallopolymeric films, Sol. Energy Mater. Sol. Cells, 25 (1992) 315325.

${ }^{39}$ P.D. Beer, O. Kocian, R.J. Mortimer, C. Ridgway, N.R. Stradiotto, Electrochemical polymerisation studies of aza-15-crown-5 vinyl-2,2'-bipyridine ruthenium(II) complexes, J. Electroanal. Chem. 408 (1996) 61-66

${ }^{40}$ P.D. Beer, O. Kocian, R.J. Mortimer, Novel mono- and di-ferrocenyl bipyridyl ligands: syntheses, electrochemistry and electropolymerisation studies of their ruthenium(II) complexes, J. Chem. Soc. Dalton Trans. (1990) 3283-3288.

${ }^{41}$ P.D. Beer, O. Kocian, R.J. Mortimer, C. Ridgway, Cyclic voltammetry of benzo-15-crown5 ether vinyl-bipyridyl ligands, their ruthenium(II) complexes and bismethoxyphenyl vinylbipyridyl ruthenium(II) complexes. Electrochemical polymerisation studies and supporting electrolyte effects, J. Chem. Soc. Faraday Trans. 89 (1993) 333-338 
${ }^{42}$ P.D. Beer, O. Kocian, R.J. Mortimer, C. Ridgway, New alkynyl- and vinyl-linked benzoand aza-crown ether-bipyridyl ruthenium(II) complexes which spectrochemically recognise group IA and IIA metal cations, J. Chem. Soc. Dalton Trans. (1993) 2629-2638.

${ }^{43}$ T. Mashiko, D. Dolphin, Porphyrins, hydroporphyrins, azaporphyrins, phthalocyanines, corroles, corrins and related macrocycles, in G. Wilkinson, R.D. Gillard, J.A. McCleverty (eds.), Comprehensive Coordination Chemistry, Pergamon, Oxford, 2, (1987), ch. 21.1. ${ }^{44}$ C.C. Leznoff, A.B.P. Lever, eds., Phthalocyanines: Properties and Applications, J. Wiley \& Sons, New York, Vol. 1 (1989); Vol. 2 (1993); Vol. 3 (1993); Vol. 4 (1996).

${ }^{45}$ D.J. Moore, T.F. Guarr, Electrochromic properties of electrodeposited lutetium diphthalocyanine thin-films, J. Electroanal. Chem. 314 (1991) 313-321.

${ }^{46}$ H.F. Li, T.F. Guarr, Reversible electrochromism in polymeric metal phthalocyanine thinfilms, J. Electroanal. Chem. 297 (1991) 169-183.

${ }^{47}$ M. Kimura, T. Horai, K. Hanabusa, H. Shirai, Electrochromic polymer derived from oxidized tetrakis(2-hydroxyphenoxy)phthalocyaninatocobalt(II) complex, Chem. Letts. 7 (1997) 653-654.

${ }^{48}$ N. Trombach, O. Hild, D. Schlettwein, D. Wöhrle, Synthesis and electropolymerisation of pyrrol-1-yl substituted phthalocyanines, J. Mater. Chem. 12 (2002) 879-885.

${ }^{49}$ N. Kashiwazaki, New complementary electrochromic display utilizing polymeric $\mathrm{YbPc}_{2}$ and Prussian blue films, Sol. Energy Mater. Sol. Cells 25 (1992) 349-359.

${ }^{50}$ R.G. Compton, A.M. Waller, P.M.S. Monk, D. R. Rosseinsky, Electron paramagnetic resonance spectroscopy of electrodeposited species from solutions of 1,1'-bis(pcyanophenyl)-4,4'-bipyridilium (cyanophenyl paraquat, CPQ), J. Chem. Soc., Faraday Trans. 86 (1990) 2583-2586.

${ }^{51}$ C.J. Schoot, J.J. Ponjee, H.T. van Dam, R.A. van Doorn, P.J. Bolwijn, New electrochromic memory display, Appl. Phys. Lett. 23 (1973) 64-65. 
${ }^{52}$ Philips Ltd., British Patent 1,302,000, (1971).

53 J.G. Kenworthy, ICI Ltd., British Patent, 1,314,049, (1973).

${ }^{54}$ D.J. Barclay, C.L. Bird, D.K. Kirkman, D.H. Martin, E.T. Moth, An Integrated electrochromic data display, SID 80 Digest, 1980, abstract 12.2, 124.

${ }^{55}$ For example, see R.J. Jasinski, n-Heptylviologen radical cation films on transparent oxide electrodes, J. Electrochem. Soc. 125 (1978) 1619-1623.

${ }^{56}$ D.J. Barclay and D.H. Martin, in Technology of Chemicals and Materials for the Electronics Industry (Edited by E. R. Howells), ch. 15. Ellis Horwood, Chichester (1984). ${ }^{57}$ M. Grätzel, Ultrafast colour displays, Nature 409 (2001) 575-576.

${ }^{58}$ D. Cummins, G. Boschloo, M. Ryan, D. Corr, S. Nagaraja Rao, D. Fitzmaurice, Ultrafast electrochromic windows based on redox-chromophore modified nanostructured semiconducting and conducting films, J. Phys. Chem. B 104 (2000) 11449-11459. ${ }^{59}$ J.M. Calvert, T.J. Manuccia, R.J. Nowak, A polymeric solid-state electrochromic cell, J. Electrochem. Soc. 133 (1986) 951- 953.

${ }^{60}$ A.F. Sammells, N.U. Pujare, Electrochromic effects on heptyl viologen incorporated within a solid polymer electrolyte cell, J. Electrochem. Soc. 133 (1986) 1270-1271.

${ }^{61}$ R.J. Mortimer, J.L. Dillingham, Electrochromic 1,1' -dialkyl-4,4'-bipyridilium-incorporated Nafion electrodes, J. Electrochem. Soc. 144 (1997) 1549-1553.

${ }^{62}$ T. Komura, T. Yamaguchi, H. Sato, H. Shimatani, K. Takahashi, Incorporation of 1,1'dibenzyl-4,4'-bipyridinium cation into Nafion films and charge transport in loaded film electrodes, Electrochim. Acta 46 (2001) 3579-3588.

${ }^{63}$ R.N. Dominey, T.J. Lewis, M.S. Wrighton, Synthesis and characterization of a benzylviologen surface-derivatizing agent - N,N'-bis[p-(trimethoxysilyl)benzyl]-4,4'bipyridinium dichloride, J. Phys. Chem. 87 (1983) 5345-5354. 
${ }^{64}$ H. Akahoshi, S. Toshima, K. Itaya, Electrochemical and spectroelectrochemical properties of polyviologen complex modified electrodes, J. Phys. Chem. 85 (1981) 818-822.

${ }^{65}$ G. Bidan, A. Deronzier, J-C. Moutet, Electrochemical coating of an electrode by a poly(pyrrole) film containing the viologen (4,4'-bipyridinium) system, J. Chem. Soc. Chem. Commun. (1984) 1185-1186.

${ }^{66}$ L. Coche, A. Deronzier, J-C. Moutet, An attempt at the preparative alkyl dibromide reduction using electrodes coated by a polypyrrole film containing the viologen $\left(4,4^{\prime}-\right.$ bipyridinium) system, J. Electroanal. Chem. 198 (1986) 187-193.

${ }^{67}$ T. Komura, T. Yamaguchi, K. Furuta, K. Sirono, Irreversible transformation of polypyrrole-bound viologen with two-electron reduction in acidic aqueous solutions, J. Electroanal. Chem. 534 (2002) 123-130.

${ }^{68}$ J. Stepp, J.B. Schlenoff, Electrochromism and electrocatalysis in viologen polyelectrolyte multilayers, J. Electrochem. Soc. 144 (1997) L155-L157.

${ }^{69}$ G.P. Evans, in H. Gerischer, C.W. Tobias (eds.), Advances in Electrochemical Science and Engineering, VCH, Weinheim, 1 (1990) 1-74.

${ }^{70}$ K. Hyodo, Electrochromism of conducting polymers, Electrochim. Acta 39 (1994) 265-272.

${ }^{71}$ J. Roncali, Conjugated poly(thiophenes): synthesis, functionalization, and applications, Chem. Rev. 92 (1992) 711-738.

${ }^{72}$ M. Mastragostino, C. Arbizzani, A. Bongini, G. Barbarella, M. Zambianchi, Polymer-based electrochromic devices. 1. Poly(3-methylthiophenes), Electrochim. Acta, 38 (1993) 135-140. ${ }^{73}$ M. Mastragostino, C. Arbizzani, P. Ferloni, A.Marinangeli, Polymer-based electrochromic devices, Solid State Ionics, 53-56 (1992) 471-478.

${ }^{74}$ M. Giglioti, F. Trivinho-Strixino, J. T. Matsushima, L.O.S. Bulhões, E.C. Pereira, Electrochemical and electrochromic response of poly(thiophene-3-acetic acid) films, Sol. En. Mater., Sol. Cells 82 (2004) 413-420. 
${ }^{75}$ L. Groenendaal, F. Jonas, D. Freitag, H. Pielartzik, J.R. Reynolds, Poly(3,4ethylenedioxythiophene) and its derivatives: past, present, and future, Adv. Mater. 12 (2000) 481-494.

${ }^{76}$ L. Groenendaal, G. Zotti, P-H. Aubert, S. M. Waybright, J. R. Reynolds, Electrochemistry of poly(3,4-alkylenedioxythiophene) derivatives, Adv. Mater. 15 (2003) 855-879.

${ }^{77}$ F. Jonas, L. Schrader, Conductive modifications of polymers with polypyrroles and polythiophenes, Synth. Met. 41-43 (1991) 831-836.

${ }^{78}$ G. Heywang, F. Jonas, Poly(alkylenedioxythiophene)s - new, very stable conducting polymers, Adv. Mater. 4 (1992) 116-118.

${ }^{79}$ S.A. Sapp, G.A. Sotzing, J.R. Reynolds, High contrast ratio and fast-switching dual polymer electrochromic devices, Chem. Mater. 10 (1998) 2101-2108.

${ }^{80}$ C.L. Gaupp, D.M. Welsh, J.R. Reynolds, Poly(ProDOT-Et-2): A high-contrast, highcoloration efficiency electrochromic polymer, Macromol. Rapid Commun. 23 (2002) 885889.

${ }^{81}$ D.M. Welsh, A. Kumar, E.W. Meijer, J.R. Reynolds, Enhanced contrast ratios and rapid switching in electrochromics based on poly(3,4-propylenedioxythiophene) derivatives, Adv. Mater. 11 (1999) 1379-1382.

${ }^{82}$ A. Kumar, D.M. Welsh, M.C. Morvant, F. Piroux, K.A. Abboud, J.R. Reynolds, Conducting poly(3,4-alkylenedioxythiophene) derivatives as fast electrochromics with highcontrast ratios, Chem. Mater. 10 (1998) 896-902.

${ }^{83}$ B. Sankaran, J.R. Reynolds, High-contrast electrochromic polymers from alkyl-derivatized poly(3,4-ethylenedioxythiophenes), Macromolecules 30 (1997) 2582-2588.

${ }^{84}$ D.M. Welsh, L.J. Kloeppner, L. Madrigal, M.R. Pinto, B.C. Thompson, K.S. Schanze, K.A. Abboud, D. Powell, J.R. Reynolds, Regiosymmetric dibutyl-substituted poly(3,4- 
propylenedioxythiophene)s as highly electron-rich electroactive and luminescent polymers, Macromolecules 35 (2002) 6517-7525.

${ }^{85}$ A. Kumar, J.R. Reynolds, Souble alkyl-substituted poly(Ethylenedioxythiophene)s as electrochromic materials, Macromolecules 29 (1996) 7629-7630.

${ }^{86}$ B.D. Reeves, C.R.G. Grenier, A.A. Argun, A. Cirpan, T.D. McCarley, J.R. Reynolds, Spray coatable electrochromic dioxythiophene polymers with high coloration efficiencies, Macromolecules 37 (2004) 7559-7569.

${ }^{87}$ A. Cirpan, A.A. Argun, C.R.G. Grenier, B.D. Reeves, J.R. Reynolds, Electrochromic devices based on soluble and processable dioxythiophene polymers, J. Mater. Chem. 13 (2003) 2422-2428.

${ }^{88}$ E.M. Genies, G. Bidan, A.F. Diaz, Spectroelectrochemical study of polypyrrole films, J. Electroanal. Chem. 149 (1983) 103-113.

${ }^{89}$ A.F. Diaz, J. I. Castillo, J.A. Logan, W.I. Lee, J. Electroanal. Chem. 129 (1981) 115-132.

${ }^{90}$ J.Y. Wong, R. Langer, D. E. Ingber, Electrically conducting polymers can noninvasively control the shape and growth of mammalian cells, Proc. Natl. Acad. Sci. USA, 91 (1994) 3201-3204.

${ }^{91}$ P. Schottland, K. Zong, C.L. Gaupp, B. L. Thompson, C.A. Thomas, I. Giurgiu, R. Hickman, K. A. Abboud, J.R. Reynolds, Poly(3,4-alkylenedioxypyrrole)s: Highly stable electronically conducting and electrochromic polymers, Macromolecules 33 (2000) 70517061.

${ }^{92}$ C.L. Gaupp, K.W. Zong, P. Schottland, B.C. Thompson, C.A. Thomas, J. R. Reynolds, Poly(3,4-ethylenedioxypyrrole): Organic electrochemistry of a highly stable electrochromic polymer, Macromolecules 33 (2000) 1132-1133. 
${ }^{93}$ G. Sonmez, I. Schwendeman, P. Schottland, K.W. Zong, J.R. Reynolds, N-substituted poly(3,4-propylenedioxypyrrole)s: High gap and low redox potential switching electroactive and electrochromic polymers, Macromolecules 36 (2003) 639-647.

${ }^{94}$ I. Schwendeman, R. Hickman, G. Sonmez, P. Schottland, K. Zong, D.M. Welsh, J.R. Reynolds, Enhanced contrast dual polymer electrochromic devices, Chem. Mater. 14 (2002) 3118-3122.

${ }^{95}$ G.A. Sotzing, J.R. Reynolds, P.J. Steel, Electrochromic conducting polymers via electrochemical polymerization of bis(2-(3,4-ethylenedioxy)thienyl) monomers, Chem. Mater. 8 (1996) 882-889.

${ }^{96}$ G.A. Sotzing, J.L. Reddinger, A.R. Katritzky, J. Soloducho, R. Musgrave, J.R. Reynolds, Multiply colored electrochromic carbazole-based polymers, Chem. Mater. 9 (1997) 15781587.

${ }^{97}$ J.A. Irvin, I. Schwendeman, Y. Lee, K.A. Abboud, J.R. Reynolds, Low-oxidation-potential conducting polymers derived from 3,4-ethylenedioxythiophene and dialkoxybenzenes, J. Polym. Sci. Pol. Chem. 39 (2001) 2164-2178.

${ }^{98}$ C.L. Gaupp, J.R. Reynolds, Multichromic copolymers based on 3,6-bis(2-(3,4ethylenedioxythiophene))-N-alkylcarbazole derivatives, Macromolecules 36 (2003) 63056315.

${ }^{99}$ C.J. Dubois, K.A. Abboud, J.R. Reynolds, Electrolyte-controlled redox conductivity in ntype doping in poly(bis-EDOT-pyridine)s, J. Phys. Chem. B 108 (2004) 8550-8557.

${ }^{100}$ C.J. Dubois, F. Larmat, D.J. Irvin, J.R. Reynolds, Multi-colored electrochromic polymers based on BEDOT-pyridines, Synth. Met. 119 (2001) 321-322.

${ }^{101}$ J.P. Ferraris, C. Henderson, D. Torres, D. Meeker, Synthesis, spectroelectrochemistry and application in electrochromic devices of n-dopable and p-dopable conducting polymer, Synth. Met. 72 (1995) 147-152. 
102 D. DeLongchamp, P.T. Hammond, Layer-by-layer assembly of PEDOT/polyaniline electrochromic devices, Adv. Mater. 13 (2001) 1455-1459.

${ }^{103}$ C.A. Cutler, M. Bouguettaya, J.R. Reynolds, PEDOT polyelectrolyte based electrochromic films via electrostatic adsorption, Adv. Mater. 14 (2002) 684-688.

${ }^{104}$ R.D. Rauh, D. Peramunage, F. Wang, Electrochemistry and electrochromism in star conductive polymers, Abstract No. 1330. 203rd Electrochemical Society Meeting, Paris, France, 27 April - 2 May, 2003. Meeting Abstracts, Volume 2003-01. Electrochromics Materials and Applications Symposium, (Symposium Organisers: A. Rougier, D. Rauh, G.A. Nazri, G. Hunter).

${ }^{105}$ R.D. Rauh, F. Wang, J.R. Reynolds, D.L. Meeker, High coloration efficiency electrochromics and their application to multi-color devices, Electrochim. Acta 46 (2001) 2023-2029.

${ }^{106}$ F. Wang, M.S. Wilson, R.D. Rauh, P. Schottland, B.C. Thompson, J.R. Reynolds, Electrochromic linear and star branched poly(3,4-ethylenedioxythiophenedidodecyloxybenzene) polymers, Macromolecules 33 (2000) 2083-2091. ${ }^{107}$ F. Wang, M.S. Wilson, R.D. Rauh, P. Schottland, J.R. Reynolds, Electroactive and conducting star-branched poly(3-hexylthiophene)s with a conjugated core, Macromolecules 32 (1999) 4272-4278.

108 T-S. Tung, K-C. Ho, A complementary electrochromic device containing 3,4ethylenedioxythiophene and Prussian blue, Abstract No. 1313. 203rd Electrochemical Society Meeting, Paris, France, 27 April - 2 May, 2003. Meeting Abstracts, Volume 2003-01. Electrochromics Materials and Applications Symposium, (Symposium Organisers: A. Rougier, D. Rauh, G.A. Nazri, G. Hunter).

${ }^{109}$ E.A.R. Duek, M-A. De Paoli, M. Mastragostino, An electrochromic device based on polyaniline and Prussian blue, Adv. Mater. 4 (1992) 287-291. 
${ }^{110}$ E.A.R. Duek, M-A. De Paoli, M. Mastragostino, A solid-state electrochromic device based on polyaniline, Prussian blue and an elastomeric electrolyte, Adv. Mater. 5 (1993) 650-652.

${ }^{111}$ M. Morita, Electrochromic behavior and stability of polyaniline composite films combined with Prussian blue, J. Appl. Poly. Sci. 52 (1994) 711-719.

112 B.P. Jelle, G. Hagen, S. Nodland, Transmission spectra of an electrochromic window consisting of polyaniline, Prussian blue and tungsten oxide, Electrochim. Acta 38 (1993) $1497-1500$.

${ }^{113}$ B.P. Jelle, G. Hagen, Transmission spectra of an electrochromic window based on polyaniline, Prussian blue and tungsten oxide, J. Electrochem. Soc. 140 (1993) 3560-3564. ${ }^{114}$ N. Leventis, Y.C. Chung, Polyaniline-Prussian blue novel composite-material for electrochromic applications, J. Electrochem. Soc. 137 (1990) 3321-3322.

${ }^{115}$ B.P. Jelle, G. Hagen, Correlation between light absorption and electric charge in solid state electrochromic windows, J. Appl. Electrochem. 29 (1999) 1103-1110.

${ }^{116}$ B.P. Jelle, G. Hagen, Performance of an electrochromic window based on polyaniline, Prussian blue and tungsten oxide, Sol. Energy Mater. Sol. Cells 58 (1999) 277-286.

${ }^{117}$ L. Wang, Q.Q. Wang, V. Cammarata, Electro-oxidative polymerization and spectroscopic characterization of novel amide polymers using diphenylamine coupling, J. Electrochem. Soc. 145 (1998) 2648-2654.

${ }^{118}$ K. Shannon, J.E. Fernandez, Preparation and properties of water-soluble, poly(styrenesulfonic acid)-doped polyaniline, J. Chem. Soc. Chem. Commun. (1994) 643-644.

${ }^{119}$ M.A. De Paoli, E.R. Duek, M.A. Rodrigues, Poly(aniline) cellulose-acetate composites conductivity and electrochromic properties, Synth. Met. 41 (1991) 973-978.

${ }^{120}$ E.L. Tassi, M.A. De Paoli, S. Panero, B. Scrosati, Electrochemical, electrochromic and mechanical-properties of the graft copolymer of polyaniline and nitrilic rubber, Polymer 35 (1994) 565-572. 
${ }^{121}$ Z. Gao, J. Bobacka, A. Lewenstam, A. Ivaska, Electrochemical-behavior of polypyrrole film polymerized in indigo carmine solution, Electrochim. Acta 39 (1994) 755-762.

${ }^{122}$ Y. Li, S. Dong, Indigo-carmine-modified polypyrrole film electrode, J. Electroanal. Chem. 348 (1993) 181-188.

${ }^{123}$ E.M. Girotto, M.A. De Paoli, Polypyrrole color modulation and electrochromic contrast enhancement by doping with a dye, Adv. Mater. 10 (1998) 790-793.

${ }^{124}$ A.F. Diaz, J.A. Logan, Electroactive polyaniline films, J. Electroanal. Chem. 111 (1980) $111-114$

${ }^{125}$ T. Kobayashi, H. Yoneyama, H. Tamura, Polyaniline film-coated electrodes as electrochromic display devices, J. Electroanal. Chem. 161 (1984) 419-423.

${ }^{126}$ A.G. MacDiarmid, A.J. Epstein, Polyanilines - a novel class of conducting polymers, Faraday Discuss. Chem. Soc. 88 (1989) 317-332.

${ }^{127}$ A. Ray, A.F. Richter, A.G. MacDiarmid, A.J. Epstein, Polyaniline - protonation deprotonation of amine and imine sites, Synth. Met. 29 (1989) 151-156.

${ }^{128}$ F. Rourke, J.A. Crayston, Cyclic voltammetry and morphology of polyaniline-coated electrodes containing $\left[\mathrm{Fe}(\mathrm{CN})_{6}\right]^{3-/ 4-}$ ions, J. Chem. Soc. Faraday Trans. 89 (1993) 295-302. ${ }^{129}$ A. Watanabe, K. Mori, Y. Iwasaki, Y. Nakamura, S. Niizuma, Electrochromism of polyaniline film prepared by electrochemical polymerization, Macromolecules. 20 (1987) 1793-1796.

${ }^{130}$ R.J. Mortimer, Spectroelectrochemistry of electrochromic poly(o-toluidine) and poly(mtoluidine) films, J. Mater. Chem. 5 (1995) 969-973.

${ }^{131}$ S. Ramirez, A.R. Hillman, Electrochemical quartz crystal microbalance studies of poly(ortho-toluidine) films exposed to aqueous perchloric acid solutions, J. Electrochem. Soc. 145 (1998) 2640-2647. 
${ }^{132}$ G-W. Jang, C.C. Chen, R.W. Gumbs, Y. Wei, J-M. Yeh, Large-area electrochromic coatings - composites of polyaniline and polyacrylate-silica hybrid set gel materials, J. Electrochem. Soc. 143 (1996) 2591-2596.

${ }^{133}$ C.A. Thomas, Donor-Acceptor methods for band gap reduction in conjugated polymers: the role of electron rich donor heterocycles, Ph.D. Thesis, Department of Chemistry, University of Florida, 2001.

${ }^{134}$ S. Sapp, G. A. Sotzing, J. R. Reynolds, High contrast ratio and fast-switching dual polymer electrochromic devices, Chem. Mater. 10 (1998) 2101-2108.

135 J.P. Ferraris, D.S.K. Mudiginda, D.L. Meeker, J. Boehme, D.C. Loveday, T.H. Dam, I.D. Brotherston, Color tailoring techniques for electroactive polymer-based electrochromic devices, Abstract No. 1329. 203rd Electrochemical Society Meeting, Paris, France, 27 April 2 May, 2003. Meeting Abstracts, Volume 2003-01. Electrochromics Materials and Applications Symposium, (Symposium Organisers: A. Rougier, D. Rauh, G.A. Nazri, G. Hunter).

${ }^{136}$ B.C. Thompson, P.Schottland, K. Zong, J.R. Reynolds, In situ colorimetric analysis of electrochromic polymers and devices, Chem. Mater. 12 (2000) 1563-1571.

${ }^{137}$ B.C. Thompson, P. Schottland, G. Sonmez, J.R. Reynolds, In situ colorimetric analysis of electrochromic polymer films and devices, Synth. Met. 119 (2001) 333-334. 